\title{
Retomando saberes contemporáneos. Un análisis del panorama actual de la meliponicultura en Tabasco
}

\author{
Reconsidering Contemporary Knowledge. \\ An Analysis of the Current Outlook of Meliponiculture in Tabasco
}

\author{
Guelmy Anilú Chan Mutul \\ Gabriela Vera Cortés \\ El Colegio de la Frontera Sur, Unidad Villahermosa \\ Elda Miriam Aldasoro Maya \\ El Colegio de la Frontera Sur, Unidad Villahermosa \\ Consejo Nacional de Ciencia y Tecnología \\ Laura Elena Sotelo Santos \\ Centro de Estudios Mayas, Instituto de Investigaciones Filológicas, \\ Universidad Nacional Autónoma de México
}

\begin{abstract}
Resumen: La meliponicultura, practiada por distintas culturas, está constituida de diversos saberes contemporáneos (conocimientos, prácticas y creencias en constante producción y reproducción). El presente estudio aborda el estado actual de la meliponicultura en Tabasco, considerándola como patrimonio biocultural. Se realizaron entrevistas semiestructuradas sobre la relación que tienen las personas con las abejas que cultivan y los saberes contemporáneos que poseen. Se registraron 101 meliponicultores en 15 de los 17 municipios, el 24\% pertenece a un grupo indígena. El municipio con mayor número de meliponicultores es el de Tenosique (37), seguido de Tacotalpa (14) y Balancán (11). Se cultivan once especies de meliponinos. Se entrevistaron 81 meliponicultores y se clasificaron en tres tipos de acuerdo a su objetivo: tradicionales (52\%), resignificados $(42 \%)$ y conservacionistas $(6 \%)$. Lo más común es tener la colmena en troncos (52\%), un $32 \%$ las tiene en cajas y un $16 \%$, tanto en troncos como en troncos modificados y cajas. El $11 \%$ de los meliponicutores sabe dividir sus colmenas. La miel, la cera y la colmena tienen diferentes usos: comestibles, medicinales y religiosos. La relación de los meliponicultores con las abejas es compleja y va más allá de lo utilitario; esta práctica implica saberes contemporáneos sobre la etología, ecología y morfología de las especies de meliponinos. Hay un declive de la meliponicultura en Tabasco por lo que es apremiante tener un mayor conocimiento de ésta y fomentarla entre las nuevas generaciones a partir de un diálogo de saberes.
\end{abstract}

Palabras clave: patrimonio biocultural, saberes, etnoentomología, meliponicultura, meliponinos. 
ABSTRACT: Meliponiculture, practiced by different cultures, is composed of diverse se contemporary knowledges (knowledge, practices and beliefs that are constantly produced and reproduced). This research investigates the current state of meliponiculture in Tabasco, considering it as a biocultural heritage. Semi-structured interviews were used to know the relationship that people have with the bees that they cultivate and the contemporary knowledge they possess. We registered 101 stingless beekeepers in 15 of the 17 municipalities, of these $24 \%$ belongs to an indigenous group. 81 stingless beekeepers were interviewed and classified in three types according to their objective: traditional $(52 \%)$, resignified $(42 \%)$ and conservationists $(6 \%)$. The community with the highest number of stingless beekeepers is Tenosique (37), followed by Tacotalpa (14) and Balancán (11). They cultivate 11 species of stingless bees. The most commom type of beehive is in log hive (52\%), $32 \%$ have them in boxes of wood and $16 \%$ in logs, modified logs and boxes. The $11 \%$ of beekeepers know how to divide their beehives. Honey, wax and hive have different uses: food, medicinal, magical-religious and ritual. The relationship between stingless beekeepers with bees is complex and goes beyond the utilitarian realm; this practice includes contemporary knowledges about the ethology, ecology and morphology of the different species of meliponines. There is a decline of meliponiculture in Tabasco so it is urgent to have a greater knowledge of it and to promote it among the new generations through a dialogue of knowledges.

KeYWords: biocultural heritage, knowledge, ethnoentomology, meliponiculture, stingless bees.

RECEPCIÓN: 28 de noviembre de 2017.

ACEPTACIÓN: 23 de abril de 2018.

DOI: 10.19130/iifl.ecm.2019.53.947.

\section{Introducción}

El cultivo ${ }^{1}$ de abejas nativas sin aguijón, meliponicultura, se remonta a tiempos pasados y ha sido practicado en las sociedades de los trópicos por generaciones. Cuando se menciona la cultura de la miel o meliponicultura se hace referencia a un fenómeno complejo que "comprende diferentes voces, conceptos, saberes, prácticas e imaginarios sobre la miel”, así como el aprovechamiento de la cera y el polen (Sotelo, Guerrero y Álvarez, 2012: 295), que se diversifica de acuerdo con las relaciones y contexto en el que se desarrolla.

En las últimas décadas varias investigaciones han documentado la estrecha relación entre la diversidad biológica y cultural, la cual queda expresada en el axioma biocultural. Esta relación establece que ambas son geográficamente coexistentes y mutuamente dependientes (Nietschmann, 1992), por lo que el término de diversidad biocultural es la mejor expresión para definirla. La conjunción de lo

${ }^{1}$ Cultivar, "Poner los medios necesarios para mantener y estrechar el conocimiento, el trato o la amistad” (Real Academia Española). 
cultural y lo biológico se refleja en valores, creencias, normas, conocimientos, lenguas y formas de subsistencia y manejo (Pretty et al., 2009: 102-103).

El término patrimonio biocultural colectivo es definido como:

los conocimientos, innovaciones, prácticas de las comunidades indígenas y locales que conviven colectivamente y están ligados inextricablemente a recursos tradicionales y territorios, economías locales, diversidad de genes, variedades, especies y ecosistemas, valores culturales y espirituales, y la creación de leyes consuetudinarias dentro de contextos socio-ecológicos de las comunidades (Swiderska, 2009: 333).

Una de las manifestaciones en la que se puede observar la relación entre lo biológico y lo cultural es precisamente la meliponicultura que se presenta en una región, parte de la cual está comprendida por saberes contemporáneos. Retomando la definición de Toledo y Alarcón-Chaires (2012), los saberes tienen su fundamento en las experiencias y valoración del mundo de acuerdo con el contexto cultural y natural en el que esté. Los elementos que conforman los saberes son kosmos (creencias), praxis (prácticas), corpus (conocimientos) y telos (finalidad). Este último término hace referencia a la finalidad de los saberes, que tiende generalmente a contribuir para lograr armonía en las relaciones comunitarias y en la vida del ser humano (Salgado, 2007).

El conocimiento ecológico tradicional, también conocido como saber indígena, se caracteriza porque entiende y explica cómo trabajan los ecosistemas, algunas interacciones entre los organismos y cómo predecir resultados respecto al uso de determinadas prácticas (Freeman, 1992). Este conocimiento se identifica por ser generalmente local, colectivo, diacrónico, holístico y dinámico (Aldasoro, 2012; Toledo 2003: 78).

México está conformado por una diversidad de saberes de los pueblos indígenas (Toledo, 2003: 78; Ávila y Vázquez, 2012). A pesar del despojo de tales conocimientos, productos y recursos naturales (Crespo y Vila-Viñas, 2015), dichos saberes forman parte de su patrimonio biocultural, por lo que deben ser reconocidos y respetados (Ávila y Vázquez, 2012). Ante esta problemática se retoma la propuesta de ecología de saberes de Santos (2010), quien la expone como una contra-epistemología, ya que promueve la idea de la diversidad epistemológica del mundo. La propuesta principal es que existen distintas formas de conocer el universo y sus componentes, las cuales implican diversos conceptos para cada forma de saber y cada una de ellas es valiosa, por lo que no debe de imponerse sobre otras.

Martínez y Rosset (2016) proponen que para el reconocimiento de los saberes se debe realizar un diálogo de saberes, el cual se define como:

La construcción colectiva de significancia emergente, basada en el diálogo establecido entre pueblos, cuyas experiencias, cosmovisiones y maneras de saber son específicas e históricamente diferentes, particularmente cuando confrontan a los nuevos desafíos colectivos de un mundo cambiante. Dicho diálogo se apoya en el 
intercambio de las diferencias y en la reflexión colectiva. A menudo, ello propicia la re-contextualización y la re-significación, lo cual da lugar a saberes y significados emergentes, que se relacionan con las historias, tradiciones, territorialidades, experiencias, procesos y acciones de los distintos pueblos. Las nuevas y colectivas comprensiones, significancias y saberes, pueden llegar a constituir la base para acciones de resistencia colectivas y para la construcción de procesos nuevos (Martínez y Rosset, 2016: 26).

Aldasoro (2012: 155) señala que los saberes deben ser llamados "saberes contemporáneos", ya que surgen de lo tradicional pero están en constante producción y reproducción, lo que significa que cambian y se adaptan a las nuevas realidades. Además, sugiere que su documentación debe ser una herramienta para la defensa de los derechos indígenas.

El estado de Tabasco cuenta con una importante diversidad biocultural, alberga a distintos grupos culturales y mestizos, así como a personas originarias de otros estados y culturas campesinas que conviven en su día a día con una considerable variedad biológica. Por ejemplo, Valdez (2008) reporta 490 especies de aves, 114 de mamíferos y 121 de anfibios y reptiles.

Las meliponiculturas tabasqueñas provienen de estos distintos grupos culturales, por lo que representan una diversidad de saberes; sin embargo, los estudios en el estado son escasos. Los pioneros fueron los de Murillo (1984) y Vásquez y Solís (1991); en ellos se observaron los conocimientos de las comunidades acerca de los usos que le daban a la miel, la cera y el polen, y reportaron una decadencia en la actividad. Más de 20 años después, Cano-Contreras, Martínez y Balboa (2013) documentaron los saberes de los choles de Tacotalpa. Posteriormente, Aldasoro, Arnold y Burguete (2015) y Aldasoro et al. (2016) documentaron los saberes meliponícolas de Tacotalpa y Comalcalco a través de un trabajo de investigación-acción participativa y observaron que, a pesar de la disminución de la meliponicultura, los saberes permanecen en la memoria de las comunidades y que había interés en retomarla. Por ello se considera que es apremiante el contar con un mayor conocimiento para poder fomentarla desde el diálogo de saberes y contribuir a su continuidad.

Ante este panorama era necesario un estudio general e interdisciplinario de la meliponicultura local, que permitiera conocer el estado actual de esta actividad en Tabasco, articulando aspectos socioculturales y ambientales con el fin de entender las necesidades y retos que los meliponicultores enfrentan para su continuidad, siendo éste el objetivo general del presente trabajo.

\section{Material y métodos}

El trabajo de campo se efectuó de febrero a junio del 2017 y consistió de dos etapas. En la primera etapa se hizo una prospección de meliponicultores en el es- 
tado, buscando apoyo de instituciones que estuvieran realizando algún proyecto sobre apicultura en la entidad y que pudieran aportar alguna información [Cruz Roja, Comisión Nacional de Áreas Naturales Protegidas (CONANP), Secretaría de Agricultura, Ganadería, Desarrollo Rural, Pesca y Alimentación (SAGARPA), ayuntamientos, sociedades apícolas, Universidad Politécnica Mesoamericana y sistemas de producción rural], y se les preguntó si tenían contacto con meliponicultores del estado. Para los municipios de Comalcalco, Nacajuca y Tacotalpa ya se contaba con algunos contactos debido a que la doctora Miriam Aldasoro desarrolla un proyecto en estas comunidades (Aldasoro, Arnold y Burguete, 2015; Aldasoro et al., 2016).

En la segunda etapa se aplicaron entrevistas semiestructuradas a los meliponicultores con experiencia identificados en la prospección, así como a otros determinados a partir de la técnica de "bola de nieve" (Valles, 2014). Para fines de esta investigación, también se entrevistaron 19 personas con experiencia en la meliponicultura, pero que no tenían colmenas en el momento de la visita. Se documentaron los siguientes aspectos: antecedentes históricos de la meliponicultura de los lugares de estudio, nomenclatura (en español y lenguas indígenas), aspectos etológicos (presencia de guardianas, horas de mayor y menor actividad, mecanismos de defensa) y aspectos ecológicos (árboles donde nidifican las abejas, árboles melíferos), así como prácticas en torno al manejo (obtención, cosecha, división, cuidados y usos). Se georreferenciaron los meliponarios encontrados a fin de elaborar un mapa. La documentación de la información se realizó en audio, escrita y por medio de fotografías. En el aspecto estrictamente biológico, se contó con el apoyo del maestro Jorge Mérida (Ecosur, San Cristóbal de las Casas) para la determinación taxonómica de las especies cultivadas (Ayala, 1999).

\section{Resultados. La meliponicultura en el pasado tabasqueño}

En los últimos 30 años, la meliponicultura en Tabasco ha cambiado por diversos factores socioculturales y ambientales, los cuales se abordarán en esta sección. Los meliponicultores señalan que antiguamente todos tenían una colmena en el corredor de su casa pero que ahora "tener colmenas" ya no es algo común. El 61\% de los entrevistados manifestaron que alguno de sus familiares tuvo abejas y que cuando eran pequeños observaban las colmenas en los corredores de sus casas.

Los testimonios de los meliponicultores registran cómo han observado en sus comunidades la disminución de esta actividad y explican que está ligada a factores como la tala excesiva del monte, la infestación tanto de moscas como de hormigas, y la presencia de abejas africanizadas. En este último punto, el $17 \%$ de los meliponicultores entrevistados señalan que han visto que esta última especie ataca y corre a sus meliponinos. Un par de ellos narraron cómo han defendido sus colmenas de ataques de abejas africanizadas. 
La gente reporta que la pérdida de monte propicia que las abejas no tengan donde hacer sus nidos, mencionan que el moté (Erythrina americana) era una de las especies donde más se hallaban nidos, pero que debido a la tala es difícil encontrar estos árboles y, por ende, a las abejas. Don Yabin (Tamulté de las Sabanas, Tabasco) menciona:

Antiguamente todos tenían porque había árboles. Todos tenían grandes colmenas porque había muchos árboles. Como todo está poblado ya no hay abejas, solamente en las rancherías. Son muy lindas, pero somos nosotros que estamos acabando con las abejas. No digo que yo, nosotros, todos.

Aunado a estos factores, también consideran que la pérdida se ha dado por la falta de interés de las nuevas generaciones en continuar la actividad. En algunos relatos mencionan que, al morir el dueño, los hijos descuidaron las abejas y éstas se fueron. Un meliponicultor de Comalcalco mencionó que los hijos de su vecino quemaron la colmena algunos años después de que su padre falleciera.

\section{El panorama actual de la meliponicultura tabasqueña}

Los municipios donde se ubicaron los meliponicultores fueron 15 de los 17 prospectados, con un total de 62 comunidades (Mapa 1). ${ }^{2}$ Se encontraron 101 meliponicultores con abejas nativas sin aguijón y 19 sin abejas, de los cuales se entrevistaron 81 del primer grupo y 19 del segundo, con un total de 101 entrevistas. La edad de los meliponicultores oscila entre los 19 y 80 años, y son de ascendencia tabasqueña $(74 \%)$, chiapaneca $(17 \%)$, campechana $(1 \%)$, veracruzana $(1 \%)$, michoacana $(5 \%)$, guerrerense $(1 \%)$, poblana $(1 \%)$ y guanajuatense $(1 \%)$. El $73 \%$ de los meliponicultores son mestizos y el $24 \%$ restante está conformado por diversos grupos indígenas originarios de Tabasco: 4\% son chontales (yokot'an), 11\% choles (laktya'ñ), 6\% tseltales (bats'il k'op), $1 \%$ mayas, $1 \%$ tlapanecos (mepha) y $1 \%$ zapotecos. ${ }^{3}$

En lo referente a su principal ocupación, los meliponicultores son campesinos $(46 \%)$, amas de casa (13\%), apicultores $(11 \%)$ y el $30 \%$ realiza otras actividades. ${ }^{4} \mathrm{El}$ encargado de cuidar la colmena puede ser hombre $(73 \%)$, mujer $(22 \%)$ o cualquier miembro de la familia (5\%). ${ }^{5}$ En Tacotalpa y Comalcalco se encontraron dos grupos de hombres y en Jonuta uno de mujeres.

\footnotetext{
${ }^{2}$ Cabe recalcar que en el municipio de Cárdenas, por motivos de seguridad, se decidió no seguir visitando las localidades.

${ }^{3}$ Los nombres de los grupos indígenas fueron revisados en el Catálogo del Instituto Nacional de Lenguas Indígenas (INALI).

${ }^{4}$ Pueden ser profesores de educación básica, estudiantes de bachillerato y licenciatura, o personas que manifestaron dedicarse a múltiples oficios.

${ }^{5}$ Estos porcentajes se obtuvieron al preguntar quién era el dueño de la colmena o principal cuidador. Cuando se habla de "cualquier miembro de la familia", es cuando la familia menciona que no había una única persona encargada de las abejas. Cada uno de los integrantes participa en las actividades que se realizan (cosecha, división y cuidados).
} 


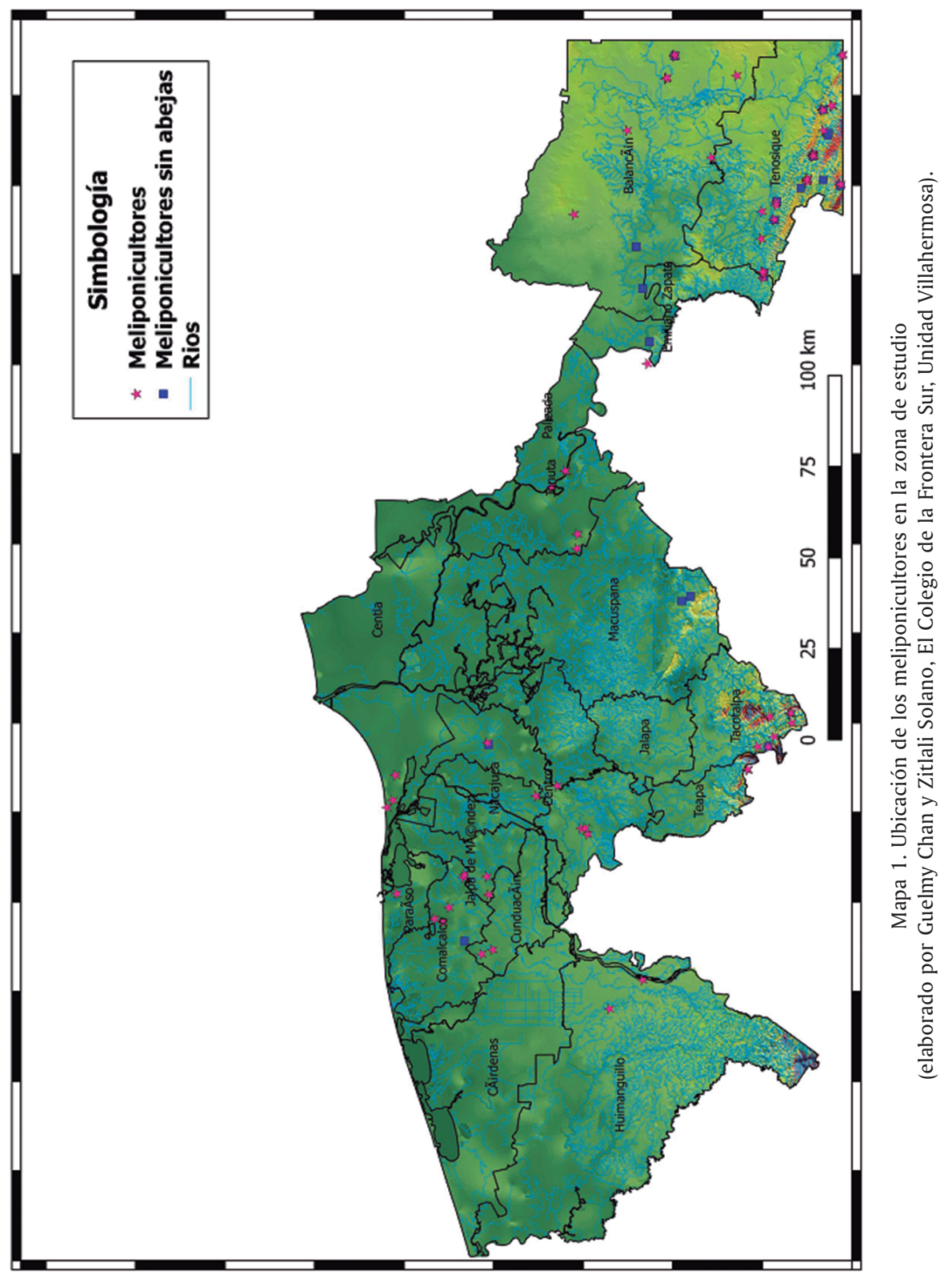


Se identificaron 11 especies que se cultivan en el estado (Tabla 1). En la nomenclatura que los meliponicultores atribuyen a las abejas consideran a las que cultivan y a las que han visto en las montañas; se registraron 15 nombres en español y 16 en lengua indígena.

\begin{tabular}{|c|c|c|}
\hline \multirow[t]{3}{*}{1,2} & Especies & Melipona becheii, Melipona solani \\
\hline & Nombres comunes en español & $\begin{array}{l}\text { Mosca real, abeja real, abeja de palo, abeja } \\
\text { de monte, criollita }\end{array}$ \\
\hline & Nombres en lengua indígena & $\begin{array}{l}\text { Ajaw chaab', chaab ajawte, chuc ox (ch'ol) } \\
\text { Ajaw chaab /ahau chab (tseltal) } \\
\text { Ñum ñum (zapoteco) } \\
\text { Xunancab (maya) } \\
\text { A'ma ekoo' (mepha) }\end{array}$ \\
\hline \multirow[t]{3}{*}{3} & Especie & Nannotrigona perilampoides \\
\hline & Nombres comunes en español & Sayul, sayulitas \\
\hline & Nombres en lengua indígena & A'ma ñojoo' (mepha) \\
\hline \multirow[t]{2}{*}{4} & Especie & Scaptotrigona pectoralis \\
\hline & Nombres comunes en español & Nopa roja, pijón \\
\hline \multirow[t]{3}{*}{5} & Especie & Frieseomelitta nigra \\
\hline & Nombres comunes en español & Abejitas, avispitas \\
\hline & Nombres en lengua indígena & A'ma dxa'aan (mepha) \\
\hline \multirow[t]{2}{*}{6} & Especie & Tetragonisca angustula \\
\hline & Nombres comunes en español & Abejitas \\
\hline \multirow[t]{2}{*}{7} & Especie & Trigona fulviventris \\
\hline & Nombres comunes en español & Señoritas \\
\hline \multirow[t]{2}{*}{8} & Especie & Trigona corvina \\
\hline & Nombres comunes en español & Cuajacabeza \\
\hline \multirow[t]{2}{*}{9} & Especie & Cephalotrigona zexmeniae \\
\hline & Nombres comunes en español & Abejitas \\
\hline
\end{tabular}




\begin{tabular}{|l|l|l|}
\hline 10 & Especie & Scaura argyrea \\
\hline & Nombre común & Sin nombre \\
\hline 11 & Especie & Plebeia $s p .^{6}$ \\
\hline & Nombre común & Sin nombre \\
\hline
\end{tabular}

Tabla 1. Nomenclatura en español y en lenguas indígenas de las abejas cultivadas en Tabasco. Fuente: Trabajo de campo.

La nomenclatura indígena a la que se tuvo acceso comprende el ch'ol, tseltal, zapoteco, mepha y maya. ${ }^{7}$ Los chontales entrevistados mencionaron no haber aprendido el vocabulario en torno a la meliponicultura. De acuerdo con Ayala (1999) y en el presente estudio se ha documentado la presencia de tres especies más en el estado (Scaptotrigona pectoralis, Frieseomelitta nigra, Tetragonisca angustula), corroborando lo reportado por Aldasoro, Arnold y Burguete (2015) y Aldasoro et al. (2016).

La gente que entrevistamos conoce la diferencia entre los meliponinos y la abeja del género Apis. Esta última es nombrada como "abeja de enjambre" (español), xux (chol), xux chaab (tseltal) y a' ma español (mepha). También se documentaron dos casos en que las abejas fueron nombradas por carácter personal. Una meliponicultora de Jalpa de Méndez nombra a sus abejas como abejulitas (Nannotrigona perilampoides) y el hijo de un meliponicultor de Tenosique, pipilitas (Melipona solani, Melipona beecheii). En general, para las especies de meliponinos que no reconocen se usa el término de "avispitas".

Se registró la presencia de otras especies de abejas sin aguijón, las cuales no se lograron observar en campo, y por lo tanto, se desconoce su especie (Tabla 2). Cano, Martínez y Balboa (2013) reportan el nombre $i k$ winik para la especie Melipona beecheii, aunque en este trabajo los entrevistados lo emplearon para hacer referencia a unas abejas negras sin aguijón.

El municipio de Tenosique es el que cuenta con el mayor número de meliponicultores (37), seguido de Tacotalpa (14) y Balancán (11). Los municipios donde se registraron menos son Jalapa (1), Nacajuca (1) y Paraíso (1). En Macuspana no se encontraron, pero se entrevistaron dos personas sin abejas, ya que tenían poco tiempo de haber perdido sus colmenas (Gráficas 1 y 2).

La temporalidad de las colmenas comprende un rango de un mes a 50 años (Gráfica 3). Sin embargo, existe una mínima diferencia entre los grupos más re-

\footnotetext{
${ }^{6}$ Esta especie fue reportada por la Universidad Politécnica Mesoamericana y por la Comisión Nacional de Áreas Naturales Protegidas (CONANP), que proveyó un listado de meliponicultores y especies del municipio de Tenosique. Hay dos casos documentados de meliponicultoras que mencionaron tener abejas del género Trigona, pero no se ha tenido acceso al meliponario para la identificación. Estos datos fueron considerados en las gráficas presentadas de especies cultivadas por municipio.

${ }^{7}$ Maya yucateco. El informante es originario de Campeche.
} 
cientes (de un mes a cuatro años) y los más antiguos (de cinco a 50 años). El primer grupo responde a los proyectos en los que se promueve el cultivo de meliponinos ${ }^{8}$ y aquellos que tuvieron antecedentes de la meliponicultura y ahora están interesados en continuar con la actividad.

\begin{tabular}{|l|l|}
\hline \multicolumn{1}{|c|}{ Nombre } & \multicolumn{1}{c|}{ Descripción } \\
\hline Kansit (tseltal) & Tipo zancudo pero amarillo \\
\hline Ik winik (tseltal, chol) & Abejitas negras \\
\hline Choy (chol) & Abejas negras con cabeza blanca \\
\hline Zunun (tseltal) & Abejas muy negras \\
\hline A'ma xinguii' (mepha) & Parecido a cuajacabeza. Vive en los nidos de las ardillas \\
\hline A'ma mbaa (mepha) & $\begin{array}{l}\text { Vive en el suelo. Cuerpo amarillo, ojos como azules, } \\
\text { alas claritas }\end{array}$ \\
\hline
\end{tabular}

Tabla 2. Relación de nombres de abejas sin aguijón descritas por los meliponicultores de Tabasco: Fuente: Trabajo de campo.

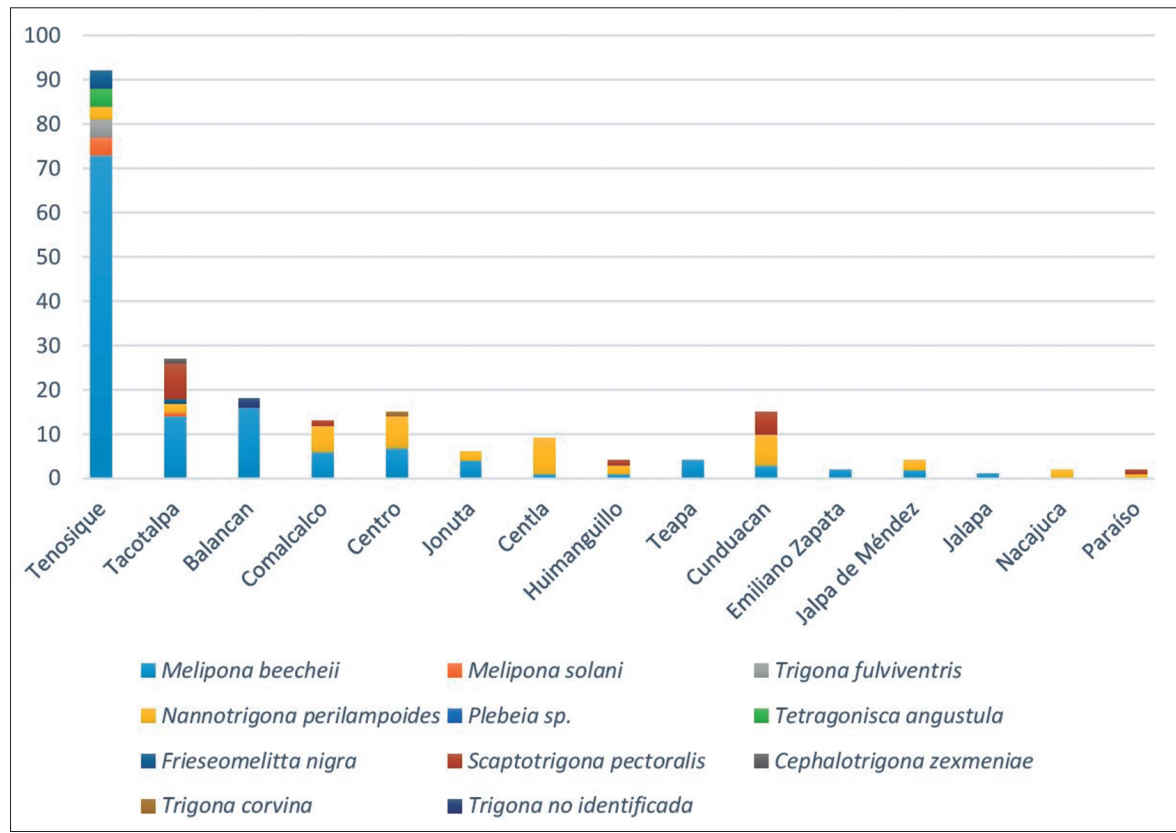

Gráfica 1. Número de colmenas por especies cultivadas por municipio de Tabasco. Fuente: Trabajo de campo.

8 Instituciones como El Colegio de la Frontera Sur, Unidad Villahermosa, Universidad Politécnica Mesoamericana, Gobierno Estatal de Tabasco y Universidad Juárez Autónoma de Tabasco. 


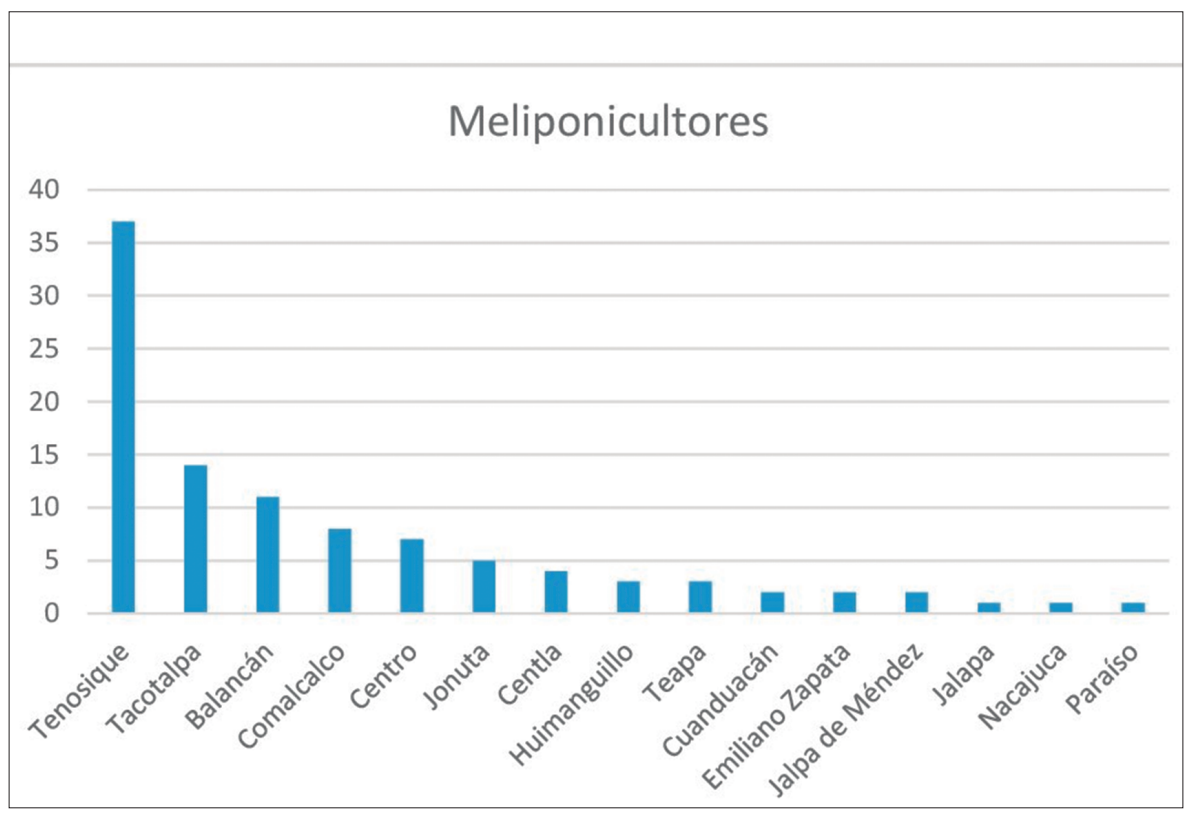

Gráfica 2. Número de meliponicultores por municipio de Tabasco. Fuente: Trabajo de campo.

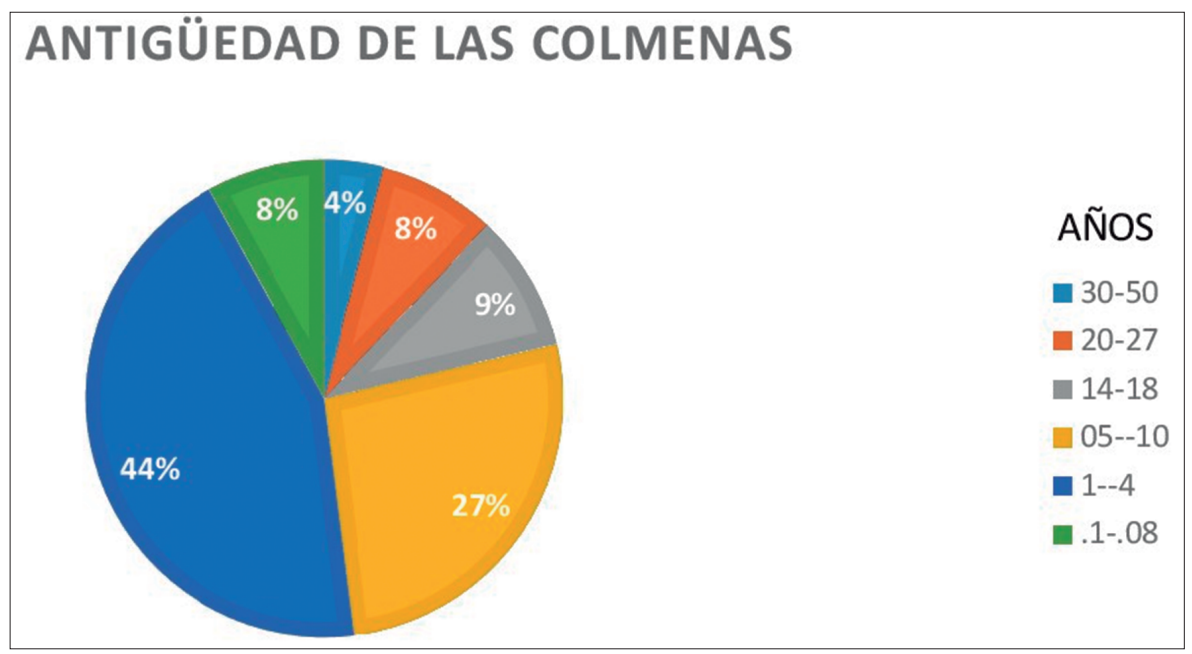

Gráfica 3. Antigüiedad de las colmenas de los casos de estudio.

Fuente: Trabajo de campo. 
Los 19 entrevistados sin colmenas asocian su pérdida a factores como la falta de vegetación, ataque de animales y cambio de tipo de colmena; cinco las perdieron por ataque de abejas africanizadas, nueve sufrieron infestaciones de moscas u hormigas y cinco de ellos mencionaron que tuvieron sus colmenas de tronco por 20 años pero que al hacer el cambio de tronco a cajas, las perdieron al poco tiempo. En esta última situación, los meliponicultores explican que a las abejas no les gusta el cambio, no se acostumbran y se van o se debilitan. Sin embargo, esto se dió porque hay una falta de información, capacitación y seguimiento respecto a los cuidados que siguen al cambio de tipo de colmenas o a la división. Los capacitadores que promueven el cambio a caja como la forma más conveniente para el manejo no explican qué amenazas tienen las abejas en este periodo de adaptación y cómo cuidarlas.

\section{Relación del ser humano con las abejas sin aguijón}

Los meliponicultores, en su relación con las abejas, pueden tener diversas percepciones y motivaciones. La miel es concebida como "más rica”, "es la miel original”, "es la miel verdadera", "es la miel que usaban nuestros padres" y "es la mejor miel”. Estas afirmaciones son atribuidas a la miel por sus propiedades medicinales y por el valor cultural e histórico. Por otra parte, las abejas son seres que deben ser respetados y valorados. Las describen como pequeñas, dóciles, nobles y organizadas. Algunos meliponicultores (21\%) les adjudicaron el poder sentir emociones o problemas. Otro meliponicultor de Tenosique mencionó que son "santas", por lo que quien desee ser meliponicultor debe tener un buen comportamiento.

La relación de los meliponicultores con las abejas ha surgido como parte de distintos procesos. Uno ha sido la valorización como parte de una herencia familiar (papá, abuelo, suegra y esposo) y por aspectos más personales. Una pareja de meliponicultores de Jonuta señaló que trajeron su colmena cuando se casaron, por lo que es un símbolo de su matrimonio de 50 años. Una meliponicultora de Jonuta comentó que su hijo tenía problemas auditivos y le recomendaron colocarlo todos los días junto a la colmena para que escuchara a las abejas, con esto se curaría; ella comentó que su hijo ahora tiene 18 años y escucha muy bien.

Ante esta cercanía, los meliponicultores observan con regularidad el comportamiento de las abejas frente a ciertas situaciones. Ellos saben que existe un número diferente de guardianas dependiendo del género, si es Melipona o Trigona. También describen que la actividad de las abejas se diferencia por el momento del día, es decir, si es de día o de noche. Por esta razón, la noche es el momento ideal para transportar las colmenas a otro espacio. Un rasgo que describen es que la Nannotrigona perilampoides por la tarde-noche cierra por completo la entrada de la colmena y la abre en la mañana para poder salir y realizar sus labores. Un mecanismo de defensa identificado es que, al no poseer aguijón, los meliponinos muerden a sus atacantes o se enredan en el cabello. 


\section{Meliponicultores tabasqueños}

Se elaboró una caracterización de los meliponicultores conforme a sus antecedentes en la meliponicultura, motivaciones y tipo de uso. Se les ha denominado de manera general como meliponicultores contemporáneos, con tres categorías: tradicionales $(52 \%)$, resignificados $(42 \%)$ y conservacionistas $(6 \%)$ (Tabla 3$)$. Debemos recalcar que el término "tradicional" no corresponde a una denominación de "antiguo", "retrasado" o "viejo", más bien se quiere hacer referencia a "normas o costumbres que tienen su raíz en el pasado y que se transmiten de generación en generación” (Real Academia Española, 2017). En este sentido, serían las personas que asocian sus abejas a sus antepasados y que continúan la actividad conservando algunos rasgos y otros pueden ser modificados.

Por otra parte, al segundo grupo se le denominó resignificado. Hacemos referencia a este término basándonos en la definición de resignificar, "dar un nuevo sentido a algo del pasado en función de algo ocurrido en el presente" (Cazau, 2014: 2213). Es decir, son meliponicultores que se iniciaron en esta actividad como parte de proyectos y que pueden tener o no algún familiar meliponicultor; las tienen para fines de conservación, ecológicos o económicos.

El tercer grupo son los conservacionistas. Tomamos este término basándonos en la definición de "alguien que tiende a conservar alguna cosa o situación determinada” (Spanish Oxford Living Dictionaries, 2018). En este sentido, son meliponicultores que tienen a sus abejas con el objetivo de conservarlas y observarlas, no realizan cosecha ni división.

\section{Las prácticas y creencias meliponícolas en Tabasco}

Retomando a Berkes (1999) y a Toledo y Alarcón (2012), los saberes se componen de prácticas, conocimientos y creencias que surgen de las experiencias del ser humano. Considerando esto, en la sección anterior se abordaron ya algunos conocimientos (sobre todo etológicos) y en las siguientes se presentarán los conocimientos ecológicos, así como las prácticas que comprenden aspectos del manejo, como la obtención, castración, división, usos y cuidados, además de las creencias (“preceptos”) $)^{9}$ que poseen los meliponicultores tabasqueños.

\section{Obtención de colmenas}

Los meliponicultores han señalado que antiguamente obtener una colmena no era una situación difícil. Cada vez que acudían a sus cacaotales o a sus "terrenos"

\footnotetext{
9 Término que usan los propios meliponicultores para hacer referencia a las creencias en torno a su actividad.
} 


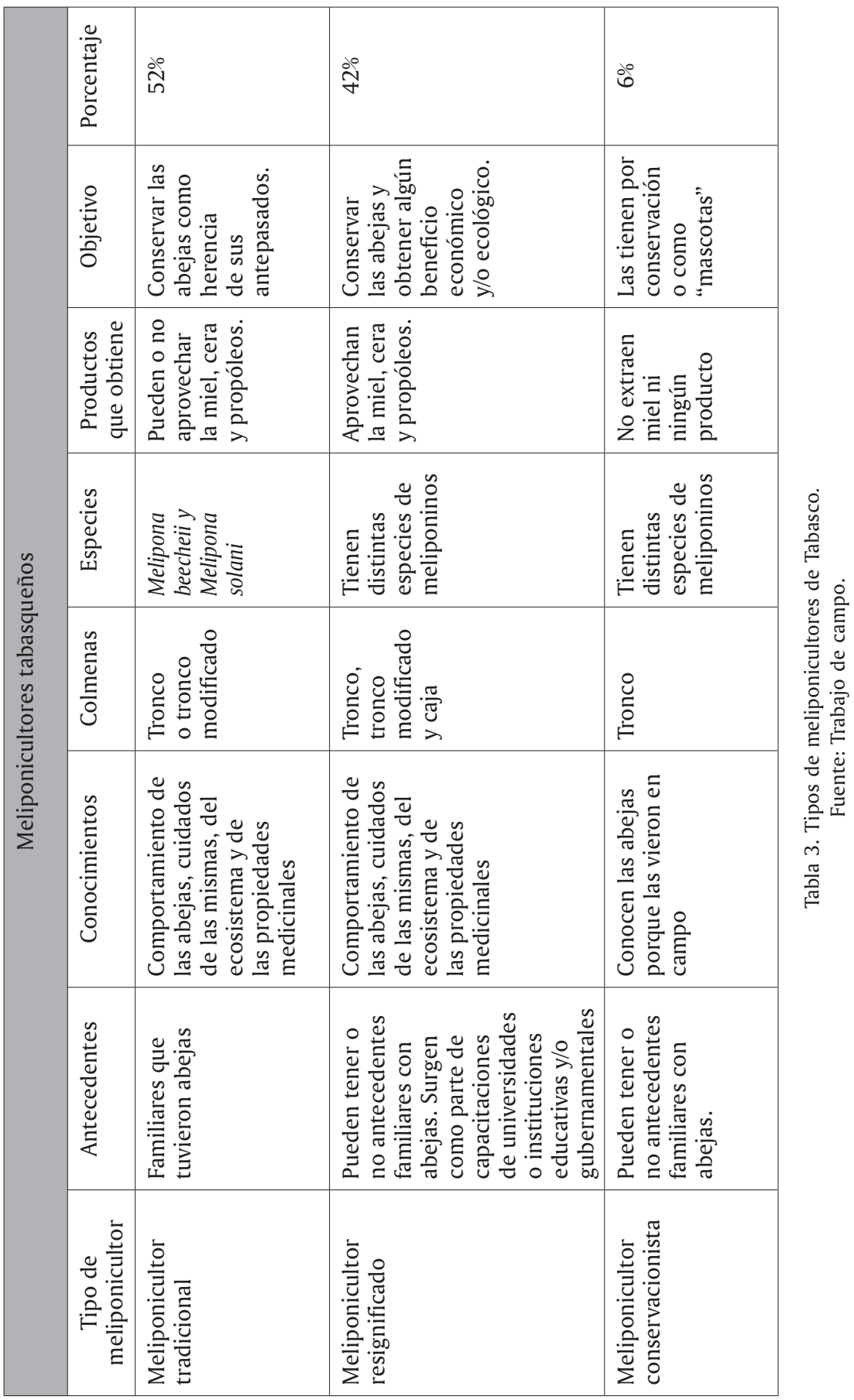


encontraban nidos. El proceso consistía en localizar los nidos, cortarlos y llevarlos hasta sus casas. Esto debía ser de noche, porque es el momento en el que todas las abejas están descansando.

Actualmente los meliponicultores emplean tres tipos de colmenas: tronco (52\%), caja (32\%) y tronco modificado (1\%), y el $15 \%$ tienen alguna combinación de estas tres modalidades (Figura 1).

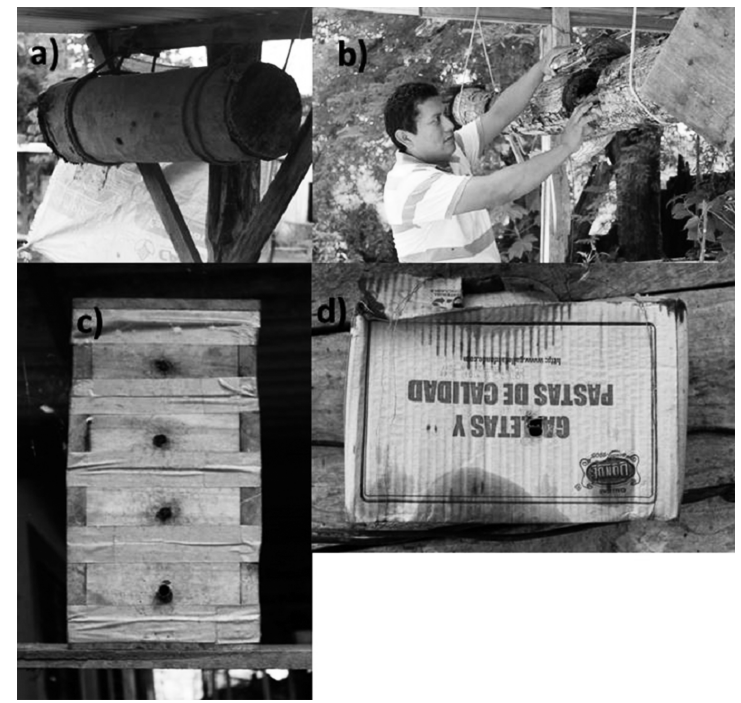

Figura 1. Tipos de colmenas. a) Tronco, b) Tronco modificado,

c) Caja, d) Caja de cartón. Fotografías de Adriana Tapia Hernández

(a), Juan José Cámara Moguel (b) y Guelmy Anilú Chan Mutul (c y d).

La elección depende de cada meliponicultor, sus necesidades y preferencias. Algunos eligen las colmenas de tronco por la herencia familiar, otros han optado por el tronco modificado, que permite tener un fácil acceso a la cría y a la miel. Otros eligen la caja por curiosidad, recomendación o porque éste fue el tipo de colmena con el que iniciaron.

Para las colmenas de tronco, señalan que deben ser árboles duros, resistentes y huecos por dentro. Los meliponicultores especifican que éstos se encuentran en las montañas y poseen un olor agradable para las abejas. Se registraron 30 especies arbóreas (Anexo I), que son empleadas como colmenas de tronco, las más comunes en los meliponarios son aguacate (Persea americana Mill), castaña (Artocarpus altilis Parkinson) y tatuán (Colubrina ferruginosa Brong.). Emplean diferentes materiales como tapas: pedazos de madera, bacales (maíz), jícaras o cáscaras de coco (Figura 2). El nombre que le atribuyen a estas colmenas también cambia: troncos, corchos o trozos, dependiendo de la comunidad. De igual forma, en tzeltal a la colmena se le dice c'humante o jobinté, en maya es jobon ché y en mepha go'oo a'ma. 


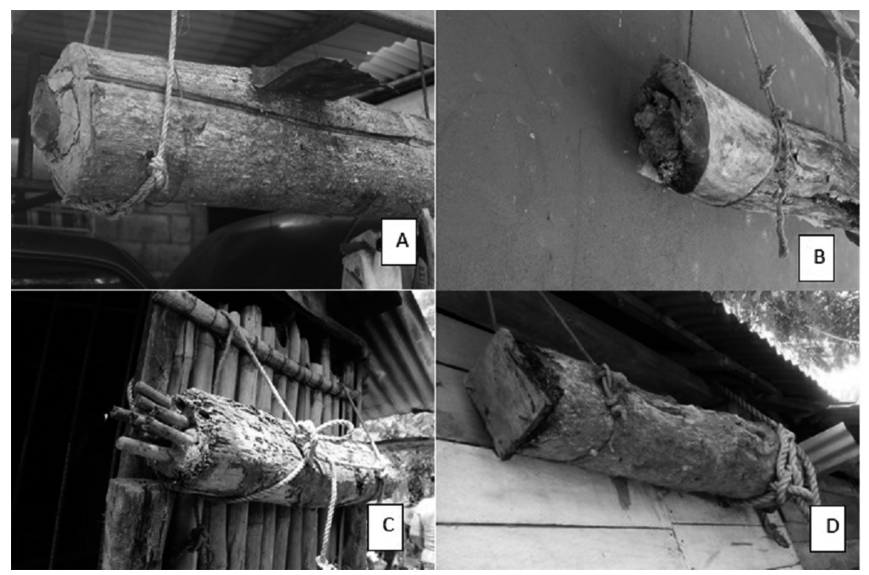

Figura 2. Tipos de tapas de colmenas de tronco. A) Jícara, B) Coco, C) Palos de madera, D) Pedazo de madera.

Fotografías de Adriana Tapia Hernández (A, C y D) y Guelmy Anilú Chan Mutul (B).

\section{Cosecha de miel}

La cosecha, llamada castración, es un proceso especial para los meliponicultores (Figura 3). Se diferencian tres tipos, que responden a la clase de colmenas, ya sea de tronco, tronco modificado o caja (Tabla 4). El proceso debe ser limpio, rápido y cumplir con creencias o preceptos asociados a las abejas, los cuales se describirán con mayor detalle más adelante. No se llegó a un consenso de algún horario específico en el que se deba realizar la cosecha. Los meliponicultores tradicionales realizan la castración en la mañana, y los demás la efectúan en el transcurso del día, después de terminar sus labores.

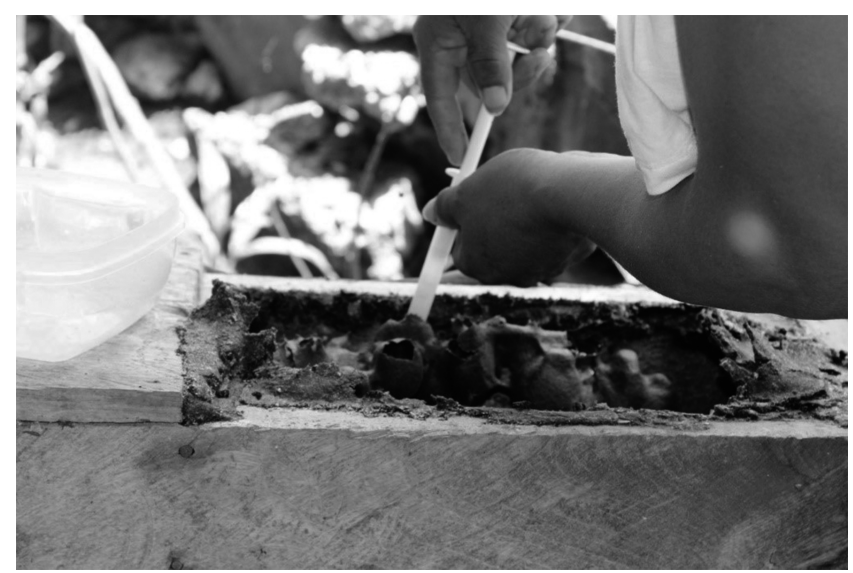

Figura 3. Castración de una caja en Tenosique, Tabasco. Fotografía de Guelmy Anilú Chan Mutul. 


\begin{tabular}{|l|l|}
\hline \multicolumn{1}{|c|}{ Tipos de castración } \\
\hline Tipo de colmena & \multicolumn{1}{c|}{ Proceso } \\
\hline Colmena de tronco & $\begin{array}{l}\text { La castración se realiza retirando las tapas laterales de la colmena. El } \\
\text { meliponicultor introduce la mano y rompe los potes, posteriormente } \\
\text { inclina la colmena para que escurra la miel a un recipiente. En otros } \\
\text { casos se extraen los potes de miel y se exprimen en algún recipiente. } \\
\text { Otros meliponicultores rompen los potes con un cuchillo o algún } \\
\text { instrumento puntiagudo, inclinan ligeramente la colmena y dejan } \\
\text { caer la miel en un recipiente. }\end{array}$ \\
\hline Tronco modificado & $\begin{array}{l}\text { En el tronco modificado se destapa la parte en la que se encuentran } \\
\text { los potes de miel. Se emplea una jeringa para succionar la miel y } \\
\text { depositarla en un recipiente. }\end{array}$ \\
\hline Caja & $\begin{array}{l}\text { En la caja, se destapa y se extrae la miel con una jeringa. La miel } \\
\text { extraída se deposita en un recipiente. }\end{array}$ \\
\hline
\end{tabular}

Tabla 4. Tipos de castración de las colmenas de Tabasco. Fuente: Trabajo de campo.

Los procesos para la castración pueden variar, pero las fechas que han sido establecidas por los meliponicultores responden a otras circunstancias. Éstas varían, pero 32 mencionan que debe ser el 2 o 3 de mayo o el 21 de abril, cuatro indicaron que en Semana Santa y los demás la realizan dos o tres veces al año incluyendo abril, junio y septiembre. Un meliponicultor chol de Tacotalpa mencionó que se basa en las fases lunares y la cosecha se realiza durante la luna menguante.

Los chontales de Tamulté de las sabanas y Nacajuca que reportaron Dávila y Solís (1991) y dos meliponicultores choles de Comalcalco relataron que este proceso era efectuado como si fuera una fiesta. En Cupilco, por ejemplo, el día 3 de mayo se realizaba la castración y repartían miel a las personas de su comunidad.

Aunados a las recomendaciones para una buena cosecha también se mencionaron algunos preceptos, los cuales definiremos como aquellas "creencias con carácter de mandatos establecidos por su sociedad” (Real Academia Española, 2014), y que deben ser cumplidos para que las abejas no se vayan. Los meliponicultores de Cunduacán, Comalcalco y Jonuta agregaron que este día todos deben portarse bien, ya que decir malas palabras hará que las abejas se vayan o que la miel se pudra. En total, el 6\% mencionó que durante la castración se debe tener un buen comportamiento por respeto a las abejas y para tener una buena cosecha de miel. Por otra parte, dos meliponicultores chontales de Jonuta señalaron que el proceso debe ser realizado por hombres, porque si una mujer lo efectúa no se obtendrá buena cantidad de miel. Los niños tampoco participan porque son "revoltosos" o pueden decir malas palabras. 
Don Yabin, de Tamulté de las Sabanas relató lo siguiente para el caso de los chontales de su comunidad:

cuando las vas a castrar primero te tienes que bañar bien, completito. Llegas, les dices yo soy tu dueño y ya puede sacar la miel. Ellas se ponían en el cabello o en la mano y ya se calmaban y ya te daban paso para poder cortar las bolsitas. Se picaban con una espina de naranja y ya cosechaban. Si quieres acompañar, puedes ir pero que no hagas ruido, que no andes insultando, que no estés diciendo malas palabras.

Por su parte, doña María, de Avispero, Emiliano Zapata, señaló que no se deben decir malas palabras durante la castración porque si no la miel desaparece.

La cantidad de miel que se cosecha ha cambiado a través del tiempo. Los meliponicultores mencionaron que antiguamente obtenían una cubeta o hasta 10 litros por colmena de "mosca real" pero que, debido a la tala de árboles, la miel que cosechan actualmente es poca. Las cantidades actuales oscilan de 0.5 a 8 litros por colmena. Las cantidades más altas de miel (8 a 10 litros) se reportan para comunidades de Tenosique, Balancán y Tacotalpa en donde es posible realizar dos cosechas de miel al año. En la región Centro, las colmenas producen de medio a un litro de miel y sólo es posible una cosecha al año. Por otra parte, de la cosecha de Trigonas obtienen medio litro.

\section{División}

La división es un proceso poco común entre los meliponicultores, solo 10 mencionaron saber cómo se realiza, uno lo aprendió de sus papás, seis a través de la capacitación y tres por experimentación. Vásquez y Solís (1991) también reportaron el éxito de un meliponicultor chontal que logró realizar la división de sus colmenas y otro que la realizó, pero perdió su colmena.

\section{Cuidados}

Los cuidados generales que los meliponicultores implementan están asociados a factores como limpieza, vigilancia, vegetación y cumplimiento de los preceptos. Según ellos, las principales amenazas ${ }^{10}$ a las que se enfrentan son el uso de pesticidas, falta de vegetación, infestaciones, ataques de animales y fumigaciones. Los químicos empleados en las fumigaciones han afectado a las abejas, ocasionando su pérdida, por ello tienen que estar vigilando y resguardando sus colmenas cuando fumigan en sus localidades.

${ }^{10}$ Esta información fue obtenida de las entrevistas a los meliponicultores. 
La falta de vegetación es otro problema que hay que considerar. Algunos manifiestan que ha repercutido en la cantidad de miel que cosechan o que la población de sus abejas no aumenta. El meliponicultor de Villahermosa ha tenido problemas con sus divisiones, ha intentado aumentar sus colmenas, pero no hay el suficiente alimento para su desarrollo, por lo que regresa los panales a la colmena madre.

Para solventar la falta de recursos, cuatro de los meliponicultores (el 4\%) han recurrido a la alimentación de colmenas. Algunos emplean miel de Apis, jarabe de azúcar y otros preparan una tortilla de polen, azúcar y levadura. Estos preparados pueden ser empleados cuando no hay floración o cuando las colmenas están débiles porque son una división o un trasiego.

Los meliponicultores recalcan que la meliponicultura debe ir junto a la reforestación. Si se quiere ser meliponicultor, se deben sembrar árboles, arbustos y plantas con flores que permitan un ambiente idóneo tanto para el ser humano como para las abejas. Por medio de las entrevistas, ellos identificaron 81 especies de flora melífera (Anexo II). Las más nombradas fueron el mango (Mangifera indica L.), el tinto (Haematoxylum campechianum L.), la naranja (Citrus sinensis) y el maculí (Tabebuia Rosea (Bertol) DC), también mencionan que todas las flores son visitadas por las abejas.

Aunado a esto, los meliponicultores han identificado árboles para nidificación, los cuales pertenecen a las regiones donde había más vegetación, lo que ellos denominan como las montañas o el monte. Si bien se enlistaron 31 especies (Anexo III), las más nombradas son aguacate (Persea americana Mill), melina (Gmelina arborea Roxb), canshán (Terminalia amazonia (J. F. Gmel.) y guapaque (Dialium guianense (Aubl.) Sandw).

\section{Creencias (preceptos)}

Existen preceptos o creencias que deben ser cumplidos por el bienestar de las abejas. Al respecto, mencionan que algunos comportamientos pueden hacer que se vayan, por lo que se debe cuidar la forma en que las personas se relacionan con los demás. Estas creencias también han sido reportadas por Vásquez y Solís (1991) para los chontales de Nacajuca y Tamulté de las Sabanas, por Cano, Martínez y Balboa (2013) para Tacotalpa, y Aldasoro, Arnold y Burguete (2015) y por Aldasoro et al. (2016) para los meliponicultores de Comalcalco y Tacotalpa.

El meliponicultor chontal de Tamulté de las Sabanas comentó que las personas que tienen abejas no deben decir malas palabras y tener un buen comportamiento. Otra afirmación reportada es que cuando el dueño de la colmena fallece, las abejas se van. Algunos meliponicultores choles de Tacotalpa mencionan que si alguien es promiscuo, borracho, dice muchos insultos, tiene malas intenciones, malas vibras o envidia, las abejas lo sienten y se puede perder la colmena. Bajo esta misma premisa, don Armando, meliponicultor de Rancho Grande, Tenosique, 
asocia la pérdida de una de sus colmenas a que la revisó una persona ajena a su familia. Su padre y su abuelo le dijeron que esto sucedió porque únicamente el propietario puede tocar a sus abejas, si no se van.

Otro meliponicultor maya, originario de Campeche, dice que las abejas son celosas y por eso se van cuando una persona es infiel. Por otra parte, hay una creencia relacionada a la pérdida de colmenas, si se van es porque el dueño va a hacer algún viaje. Pero, en Jonuta, mencionan que si esto sucede es porque vendrán problemas familiares, algún divorcio o muerte.

\section{Usos}

La meliponicultura como patrimonio biocultural aporta cinco elementos de importancia utilitaria: la miel, la cera, el polen, los propóleos y la colmena como tal. Los usos actuales de los productos obtenidos de los meliponinos se enfocan en la preparación de remedios medicinales, alimenticios, artefactuales y rituales (Tabla 5), y corresponden en su mayoría a los usos antiguos, que se han transmitido a través de generaciones. Estos usos han sido reportados por Vásquez y Solís (1991), Cano, Martínez y Balboa (2013), Aldasoro, Arnold y Burguete (2015) y Aldasoro et al. (2016).

El producto más empleado es la miel. El 59\% de los meliponicultores entrevistados la emplean para consumo familiar, en la preparación de remedios o para endulzar sus alimentos, el $45 \%$ la utiliza en el hogar y para la venta, el $10 \%$ no saca la miel y el $4 \%$ la usa para venta. Se documentó el uso de la miel para tratar 26 padecimientos, de los cuales son mencionados en las comunidades la relajadura del cuajo y la sacanaca. ${ }^{11}$ La primera es descrita como un padecimiento de los niños pequeños en el cual presentan vómitos y diarrea, y se origina porque las mamás consumen algún alimento ácido o tienen problemas al amamantar a los niños. La sacanaca es un hongo que aparece en las encías de los bebés y que se describe como un sarro. Por otra parte, algunos meliponicultores de Comalcalco mencionaron que no se debe exceder en el consumo de la miel, pues en grandes cantidades emborracha, pues ellos y sus familiares ya lo han experimentado.

El segundo producto usado es la cera. Se emplea en el ámbito medicinal, religioso y para la elaboración de velas.

\section{Discusión y consideraciones finales}

En 1984 Murillo reportó una decadencia de la meliponicultura de Tabasco; a pesar de ello, en este estudio aún se observa la presencia de meliponicultores en el estado que señalan la importancia de conservar la actividad y a las abejas. Al

${ }^{11}$ También se le conoce como algodoncillo. 


\begin{tabular}{|c|c|c|c|c|c|}
\hline Producto & Uso & $\begin{array}{l}\text { Condición a } \\
\text { tratar }\end{array}$ & $\begin{array}{l}\text { Forma de } \\
\text { uso }\end{array}$ & Forma de aplicación & Grupo \\
\hline \multirow{24}{*}{ Miel } & \multirow{21}{*}{ Medicinal } & $\begin{array}{l}\text { Gastritis, dolor } \\
\text { de estómago }\end{array}$ & \multirow{4}{*}{ Oral } & $\begin{array}{l}\text { Mezclar con sábila y } \\
\text { tomarlo por las mañanas }\end{array}$ & Mestizo ch'ol \\
\hline & & $\begin{array}{c}\text { Inflamación en la } \\
\text { garganta }\end{array}$ & & Mezclar con limón & Mestizo ch'ol \\
\hline & & \multirow{2}{*}{ Tos, gripe } & & $\begin{array}{l}\text { Mezclar con maguey, } \\
\text { cebolla y limón }\end{array}$ & Ch'ol mestizo tzeltal \\
\hline & & & & Miel con limón & Mestizo ch'ol \\
\hline & & $\begin{array}{c}\text { Quemaduras, } \\
\text { heridas de los } \\
\text { diabéticos o } \\
\text { difíciles de curar }\end{array}$ & Cutánea & Se unta sobre la herida & $\begin{array}{l}\text { Mestizo tzeltal } \\
\text { chontal ch'ol }\end{array}$ \\
\hline & & $\begin{array}{l}\text { Relajadura del } \\
\text { cuajo }\end{array}$ & \multirow{2}{*}{ Oral } & $\begin{array}{l}\text { Se mezcla guayaba, } \\
\text { coco y algunas plantas } \\
\text { silvestres }\end{array}$ & Mestizo \\
\hline & & Asma & & $\begin{array}{l}\text { Miel sola o mezclada con } \\
\text { manteca de lagarto }\end{array}$ & Mestizo \\
\hline & & $\begin{array}{c}\text { Cataratas, } \\
\text { Carnosidad, Vista } \\
\text { cansada }\end{array}$ & Oftálmicas & Gotas en los ojos & $\begin{array}{l}\text { Ch'ol mestizo } \\
\text { chontal Tzeltal }\end{array}$ \\
\hline & & Úlcera & Oral & Se ingiere & Mestizo \\
\hline & & Cáncer & Oral & Se ingiere & Mestizo \\
\hline & & Sacanaca & \multirow{3}{*}{ Cutáneo } & $\begin{array}{l}\text { Se frota las encías con } \\
\text { un pañuelo }\end{array}$ & Chontal mestizo \\
\hline & & Granos en la cara & & Se unta como mascarilla & Mestizo \\
\hline & & Labios partidos & & Se unta en los labios & Mestizo \\
\hline & & $\begin{array}{l}\text { Vigorizante } \\
\text { sexual }\end{array}$ & Oral & Mezclar con el polen & Ch'ol \\
\hline & & Hemorroides & Cutáneo & $\begin{array}{l}\text { Se unta en la parte } \\
\text { afectada }\end{array}$ & Ch'ol \\
\hline & & $\begin{array}{l}\text { Problemas del } \\
\text { hígado }\end{array}$ & Oral & Se ingiere la miel & Ch'ol \\
\hline & & $\begin{array}{c}\text { Problemas con la } \\
\text { próstata }\end{array}$ & Oral & $\begin{array}{l}\text { Se ingiere la miel sola o } \\
\text { con polen }\end{array}$ & Ch'ol mestizo \\
\hline & & Neumonía & Oral & $\begin{array}{l}\text { Se mezcla con limón y } \\
\text { vino de jerez }\end{array}$ & Mestizo \\
\hline & & $\begin{array}{l}\text { Bichos en el } \\
\text { estómago }\end{array}$ & Oral & $\begin{array}{l}\text { Se ingiere una mezcla de } \\
\text { miel con ajo }\end{array}$ & Ch'ol \\
\hline & & Mujeres en parto & $\begin{array}{l}\text { Cutáneo y } \\
\text { oral }\end{array}$ & $\begin{array}{l}\text { Como lubricante } \\
\text { o ingerido como } \\
\text { vitamínico }\end{array}$ & Ch'ol mestizo \\
\hline & & $\begin{array}{l}\text { Curar aves } \\
\text { domésticas }\end{array}$ & Oral & $\begin{array}{l}\text { Le dieron miel para la } \\
\text { tos de los pollitos }\end{array}$ & Mestizo \\
\hline & \multirow{3}{*}{ Alimento } & \multirow{3}{*}{ Alimento } & \multirow{3}{*}{ Oral } & Endulzar pozol & Mestizo tzeltal \\
\hline & & & & Hacer dulces & Mestizo \\
\hline & & & & Endulzar alimentos & Mestizo \\
\hline
\end{tabular}




\begin{tabular}{|c|c|c|c|c|c|}
\hline \multirow{11}{*}{ Cera } & Medicinal & Quemaduras & Cutáneo & $\begin{array}{l}\text { Se hace una pasta y se } \\
\text { coloca sobre la herida }\end{array}$ & Chontal \\
\hline & \multirow{6}{*}{ Ritual } & $\begin{array}{l}\text { Calentamiento } \\
\text { de la mollera }\end{array}$ & & $\begin{array}{l}\text { Se coloca una bolita en } \\
\text { la mollera }\end{array}$ & Ch'ol \\
\hline & & $\begin{array}{l}\text { Protección de } \\
\text { males }\end{array}$ & & $\begin{array}{l}\text { Se quema la cera y se } \\
\text { sahuma a los bebés }\end{array}$ & Ch'ol mestizo \\
\hline & & \multirow{3}{*}{ Velas } & & Para los difuntos & Mestizo chontal \\
\hline & & & & $\begin{array}{l}\text { Alumbrar sus hogares: } \\
\text { no había luz o alguna } \\
\text { catástrofe natural }\end{array}$ & Zapoteco mestizo \\
\hline & & & & Eclipses & Ch'ol \\
\hline & & Difuntos & & $\begin{array}{l}\text { Se colocan bolitas de } \\
\text { cera en el amarre de los } \\
\text { difuntos }\end{array}$ & Ch'ol \\
\hline & \multirow{4}{*}{ Artefactual } & Reparar trastes & & $\begin{array}{l}\text { Se ponen parches en la } \\
\text { olla o vasija }\end{array}$ & Mestizo \\
\hline & & $\begin{array}{l}\text { Reparar los } \\
\text { cuernos del } \\
\text { ganado }\end{array}$ & & $\begin{array}{l}\text { Se ponen parches en } \\
\text { las partes donde esté } \\
\text { afectado el cuerno }\end{array}$ & Chontal \\
\hline & & $\begin{array}{l}\text { Reparar } \\
\text { monturas de los } \\
\text { caballos }\end{array}$ & & Se usa como parche & Chontal \\
\hline & & Costurar zapatos & & $\begin{array}{l}\text { Para el hilo con el que se } \\
\text { costuran los zapatos }\end{array}$ & Mestizos \\
\hline Polen & Alimento & Vitamínico & Oral & $\begin{array}{l}\text { Se licua con polen y se } \\
\text { ingiere }\end{array}$ & Chontal mestizo \\
\hline Colmena & Medicinal & $\begin{array}{l}\text { Problemas de } \\
\text { audición }\end{array}$ & & $\begin{array}{l}\text { La persona pone el oído } \\
\text { en la colmena dos veces } \\
\text { al día }\end{array}$ & Mestizo \\
\hline Propóleos & Medicinal & Asma & Oral & Propóleos con alcohol & Mestizo \\
\hline
\end{tabular}

Tabla 5. Usos de la miel, cera, polen y colmena por los meliponicultores de Tabasco. Fuente: Trabajo de campo.

respecto, se quiere recalcar que no existe una sola forma de realizar la meliponicultura, ya que responde a diferentes motivaciones y necesidades, por lo que proponemos la coexistencia de meliponiculturas.

Retomando a Toledo (2005, 2013), los saberes son colectivos, aunque en el caso de Tabasco no son locales, ya que convergen distintos grupos indígenas y de otros estados. Para entender la dinámica de los saberes retomamos la propuesta de Aldasoro (2012: 155) al denominarlos contemporáneos ya que responden a procesos de cambio que pueden ser culturales, sociales, económicos y/o ambientales. La diversidad puede estar relacionada por el ámbito cultural en el que 
la meliponicultura se desarrolla. Por ejemplo, los actores principales de la meliponicultura tabasqueña son grupos choles, tzeltales, chontales y mestizos que manifiestan saberes propios de sus contextos culturales, pero también comparten algunos rasgos. Estas similitudes y diferencias son resultado de la interacción de los grupos, ya que como Santos (2010) ha señalado, los saberes interactúan, se entrecruzan y no pueden ser comparados entre ellos.

Los preceptos y creencias en torno a las abejas son compartidos por los grupos debido a su origen histórico y a que pertenecen a la cultura maya. En el contexto de la cosmovisión del área maya prehispánica y colonial, las abejas eran seres sagrados protegidos por diversas deidades, a las cuales los hombres debían dirigirse si se quería establecer un meliponario, pedir permiso y agradecer por la cosecha (Carrillo, 2002; Thompson, 1975; Castillo, 1972). De igual modo, la medicina prehispánica estuvo relacionada con la religión. Los mayas consideraban que las enfermedades se originaban por causas naturales o sobrenaturales como los vientos malos, los astros o el enojo de los dioses (Kocyba, 1993; Xiu-Chacón, 1998). En este sentido, las enfermedades debían ser curadas por los sacerdotes, y entre los remedios que empleaban estaban las abejas y sus productos (Ruz, 1995).

Muchas de estas creencias aún sustentan las ideas de los meliponicultores actuales, que señalan que las abejas son seres sagrados y santos que deben ser respetados y, por ende, el dueño debe tener un comportamiento intachable. La miel y la cera también son considerados parte de los elementos medicinales empleados para la curación de enfermedades corporales y cosmogónicas.

La diversidad de los grupos presentes en el estado es el resultado de procesos históricos que tuvieron inicio desde tiempos prehispánicos, en los que distintas sociedades entraron en contacto (Vaultravers y Ochoa, 2008). Por otra parte, tres procesos recientes tuvieron impacto en el ámbito socioeconómico y ambiental de Tabasco: El Plan Chontalpa, El Plan Balancán-Tenosique y el auge petrolero (Lezama, 1987; Tudela, 1992). En los planes hubo modificaciones como la deforestación, reubicación de las familias, reestructuración de la tenencia de la tierra y lo que Tudela (1992) llamó la eliminación de los conocimientos locales que para los planes no resultaban funcionales.

Otro rasgo que influye en la dinámica de los saberes es la edad de los meliponicultores. Las personas más jóvenes sustentan sus motivaciones con fines de conservación, aprendida en el ámbito escolar. Además, son los que tienden a emplear las redes sociales para solucionar problemas e innovar sus colmenas. En el presente estudio y los realizados por Aldasoro, Arnold y Burguete (2015), Vásquez y Solís (1991) y Cano, Martínez y Balboa (2013) se observó que los adultos mayores comparten el objetivo de preservar sus colmenas como parte de la tradición de sus familias. Aunado a esto, el grupo más variable es el de los adultos, los cuales tienen antecedentes familiares en la actividad, emplean las redes y son los más considerados en los proyectos de capacitación.

Sin embargo, no hay que dejar de lado que los meliponicultores tienen ideas y propósitos personales. Por tanto, son agentes que propician cambios. Esto pode- 
mos observarlo cuando manifiestan sus inquietudes en el manejo de sus abejas o cuando hacen experimentos con las colmenas, como el caso de los troncos modificados. Ante estas dinámicas, Santos (2010) considera que el aprender nuevas formas de conocimiento puede propiciar el olvido de otras. En este trabajo, esto no se considera del todo cierto; más bien, se complementan.

Desde el contexto de los meliponicultores, se identifican factores que han propiciado el cambio de dicha actividad en el estado. Ellos mencionaron que la deforestación, el uso de plaguicidas y la urbanización son las principales razones por las que las abejas se han perdido. Para la solución de estas problemáticas se debe considerar que las comunidades, a través de sus saberes, han jugado un papel clave en la conservación de la biodiversidad (Argueta, 2011). Entonces, hay que entender que los conocimientos de los meliponicultores deben ser respetados y considerados como clave para crear el contexto adecuado para las abejas. Se propone que, para impulsar las meliponiculturas, las nuevas iniciativas sean más integrales y que engloben factores sociales, culturales, económicos, biológicos y ambientales, además de que fomenten prácticas agroecológicas.

¿Deberíamos preguntarnos por qué van de la mano la agroecología y la meliponicultura? La agroecología es una disciplina que estudia las relaciones socioeconómicas, procesos biológicos y ecológicos de los sistemas agrícolas. Retoma prácticas tradicionales y locales que propicien el aumento en la producción y la mejora de cada sistema. Uno de sus objetivos es la disminución de los plaguicidas y el aumento de los policultivos, los cuales mejoran la calidad del suelo y lo hacen más eficiente (Altieri y Nicholls, 2000; Silici, 2014). Gliessman (2013) señala que en esta disciplina se debe promover un movimiento social que honre la parte cultural y ambiental por medio del respeto de la diversidad de conocimientos ecológicos de las comunidades.

Los meliponicultores, en su mayoría, se dedican al campo, por lo que se debe buscar un beneficio para sus abejas y para ellos. En este sentido, tomando en cuenta las propuestas de la agroecología, las abejas, siendo polinizadoras de plantas nativas, con los listados que los meliponicultores proveen, sirven para diseñar sistemas agroecológicos que beneficien el suelo, que promuevan la diversidad en los sistemas agrícolas, que aumenten la producción de miel y tengan colmenas más fuertes y saludables.

En las entrevistas se les cuestionó a los meliponicultores qué les gustaría hacer en los próximos años con sus abejas, ellos mencionaron que lo importante es la conservación y el aumento, por la relevancia cultural y ecológica, así como por la disminución de la actividad y las abejas. En este punto se debe promover que el aumento de colmenas debe estar ligado a su división y no a la extracción de colmenas silvestres que implican la tala de árboles. 


\section{Problemas de la meliponicultura ante la diversidad de saberes}

En los resultados de esta investigación, y en otros trabajos enfocados en Tabasco, se reportó que las comunidades han tenido problemas respectos a su patrimonio biocultural (saberes y recursos), como la falta de respeto hacia sus conocimientos y el despojo de sus recursos (Boege, 2008; Aldasoro, 2012). Los meliponicultores señalan que han tenido roces con algunas instituciones debido a que éstas trataron de imponerles ideas para "modernizar" sus colmenas o porque les prometieron recursos. Estos cambios que intentan implementarse en el estado reflejan la falta de entendimiento de la diversidad y el valor que tienen los saberes. En las entrevistas a actores externos se manifestó una falta de interés en apoyar la meliponicultura porque no genera ingresos o no es importante para la economía del estado.

Los elementos principales que se resaltan en esta investigación son los que integran las meliponiculturas: las abejas y los saberes de las comunidades. Por ello, se recalca la importancia de su conservación y el hecho de que para su preservación no deben ser entendidos como aspectos aislados. Ante las problemáticas de negación, Negrín y Sotelo (2016) proponen que la meliponicultura tiene cabida dentro del patrimonio, ya que engloba tradiciones, distintos tipos de usos, conocimientos relacionados con la naturaleza y técnicas artesanales tradicionales y modernas. Desde esta perspectiva, se pueden implementar diversas herramientas que el patrimonio biocultural ofrece para su resguardo y protección (Aldasoro, 2015).

El diálogo de saberes es una de las herramientas propuestas. Se debe dar un diálogo entre los meliponicultores en el que compartan sus conocimientos. Pero es importante que este diálogo se realice con investigadores e instituciones, y que en él se reconozcan y respeten los saberes meliponícolas locales para su difusión y continuidad en el estado.

\section{Agradecimientos}

Queremos agradecer principalmente a los meliponicultores que participaron brindándonos su tiempo y experiencias. Al proyecto FORDECYT "Cambio global y sustentabilidad en la Cuenca del Usumacinta y zona marina de influencia, bases para la adaptación al cambio climático desde la ciencia y la gestión del territorio", a cargo del Dr. Hans van der Wal. A los compañeros y amigos que nos acompañaron en las entrevistas. A la Dirección del Área de Protección de Flora y Fauna del Cañón del Usumacinta, Universidad Politécnica Mesoamericana, las asociaciones BACAB (Tenosique), Alianza Estratégica para el Desarrollo Sustentable Microrregión Agua Blanca (Macuspana) y Agencia para el Desarrollo Humano la Sierra (Tacotalpa), por apoyar en la búsqueda de meliponicultores. Al Mtro. Jorge Mérida (Ecosur, SCLC) por la determinación taxonómica y al biólogo Eduardo Montejo 
Olan por su ayuda en la identificación de abejas y árboles melíferos y para nidificación. Al proyecto PAPIT IG400317, Plantas sagradas de los mayas, de la UNAM.

\section{Bibliografía}

Aldasoro Maya, Elda Miriam

2012 "Documenting and Contextualizing Pjiekakjoo (Tlahuica) Knowledges through a Collaborative Research Project", tesis de para optar por el grado de Doctor of Philosophy. Washington: University of Washington.

Aldasoro Maya, Elda Miriam, Noemí Arnold y Corina Yuriet Burguete Rosales

2015 "Los meliponinos de Comalcalco, Tabasco, una primera aproximación desde el enfoque biocultural", ponencia presentada en el IX Congreso Mexicano de Etnobiología, San Cristóbal de las Casas.

Aldasoro Maya, Elda Míriam, Teresita Avilez López, Gabriela Vera Cortés y Johannes Van der Wal

2016 "Saberes contemporáneos, meliponinos y escalamiento de la agroecología: reconociendo paisajes culturales", ponencia presentada en el $X$ Congreso Mexicano de Etnobiología, Mérida.

Altieri, Miguel y Clara I. Nicholls

2000 Agroecología: teoría y práctica para una agricultura sustentable. Ciudad de México: Programa de las Naciones Unidas para el Medio Ambiente, Red de Formación Ambiental para América Latina y el Caribe (Serie Textos Básicos para la Formación Ambiental, 4).

Antweiler, Christopph

1998 "Local Knowledge and Local Knowing An Anthropological Analysis of Contested "Cultural Products" in the Context of Development", Anthropos, 93: 469-494. DOI: $10.2307 / 40464844$.

Argueta Villamar, Arturo, Eduardo Corona y Paul Hersch Martínez (coords.)

2011 Saberes colectivos y diálogo de saberes en México. Cuernavaca, Puebla: Centro Regional de Investigaciones Multidisciplinarias, Universidad Nacional Autónoma de México, Universidad Iberoamericana.

Ávila Romero, Agustín y Luis Daniel Vázquez (coords.)

2012 Patrimonio biocultural, saberes y derechos de los pueblos originarios. San Cristóbal de las Casas: Consejo Latinoamericano de Ciencias Sociales, Universidad Intercultural de Chiapas, Programa de Mejoramiento del Profesorado, Instituto Nacional de Lenguas Indígenas.

Ayala, Ricardo

1999 "Revisión de las abejas sin aguijon de México (Hymenoptera: Apidae: Meliponini)", Folia Entomológica Mexicana, 106: 1-123. 
Berkes, Fikret

1999 Sacred Ecology: Traditional Ecological Knowledge and Resource Management. Quebec: Taylor and Francis.

Boege, Eckart

2008 El patrimonio biocultural de los pueblos indígenas de México. Hacia la conservación in situ de la biodiversidad y agrodiversidad en los territorios indígenas. México: Instituto Nacional de Antropología e Historia, Comisión Nacional para el Desarrollo de los Pueblos Indígenas.

Cano Contreras, Eréndira Juanita, Chrystian Martínez Martínez y Carlos Cesar Balboa Aguilar

2013 "La abeja de monte (Insecta: Apidae, Meliponini) de los choles de Tacotalpa, Tabasco: conocimiento local, presente y futuro", Etnobiología, 11: 47-57.

Carrillo Magaña, Felipe A.

2002 Terminologías maya-yucatecas referentes a la cría de abejas sin aguijón. Mérida: Instituto de Cultura de Yucatán, Dirección General de Culturas Populares.

Castillo Calero, Alberto

1972 "Yucatán, tierra de fibras y de miel", Revista de la Universidad Autónoma de Yucatán, XIV: 91-130.

Cazau, Pablo

2014 Vocabulario de Psicología, <https://sites.google.com/site/pcazau/Home>, [consultada el 20 de mayo del 2018].

Crespo, Juan Manuel y David Vila-Viñas

2015 Comunidades: saberes y conocimientos originarios, tradicionales y populares. Buen Conocer - FLOK Society. Modelos sostenibles y políticas públicas para una economía social del conocimiento común y abierto en el Ecuador. Quito: Instituto de Altos Estudios Nacionales, Centro Internacional de Estudios Superiores de Comunicación para América Latina (Línea 3: Institucionalidad, sociedad y comunidades. Documento de política pública 3.2).

Freeman, Milton M. R

1992 "The Nature and Utility of Traditional Ecological Knowledge", Northern Perspectives, 21 (1): 9-12.

Gliessman, Stephen R.

2013 "Agroecología: plantando las raíces de la resistencia”, Agroecología, 8: 19-26.

Instituto Nacional de Lenguas Indigenas (INALI)

2008 Catálogo de Lenguas Indígenas Nacionales: variantes lingüisticas de México con sus autodenominaciones y referencias geoestadísticas, Diario Oficial de la Federación, <http://www.inali.gob.mx/pdf/CLIN_completo.pdf > [consultado el 20 de septiembre del 2017]. 
Kocyba, Henryk Karol

1993 "La religión y la medicina maya posclásica", III Coloquio de Historia de la religión en Mesoamérica y áreas afines, pp. 69-80, Barbro Dahlgren (comp.). México: Universidad Nacional Autónoma de México, Instituto de Investigaciones Antropológicas, Pangea Editores.

Lezama, José Luis

1987 “Migración y petróleo en Tabasco", Estudios Demográficos y Urbanos, 2 (2): 231-256.

Martínez Torres, María Elena y Peter M. Rosset

2016 "Diálogo de saberes en la vía campesina: soberanía alimentaria y agroecología”, Espacio Regional, 1 (13): 23-36.

Meléndez Ramírez, Virginia, Laura Meneses Calvillo y Peter G. Kevan

2013 "Effects of Human Disturbance and Fragmentation on Stingless Bee", PotHoney: A Legacy of Stingless Bees, pp. 269-283, Patricia Vit, Silvia R. M. Pedro y David Roubik (eds.). New York: Springer.

Murillo Martínez, Rosa María

1984 "Uso y manejo actual de las colonias de Melipona beecheii Bennett (Apidae: Meliponini) en el estado de Tabasco, México”, Biotica, 9: 423-428.

Negrín Muñoz, Eduardo y Laura Elena Sotelo Santos

2016 "Abejas nativas, señoras de la miel. Patrimonio cultural en el estado de Campeche", Revista Iberoamericana de las Ciencias Sociales y Humanísticas, 5 (9): 162-185.

Nietschmann, Bernard Q.

1992 The Interdependence of Biological and Cultural Diversity. Kenmore: Center for World Indigenous Studies (Ocassional Paper, 21).

Pretty, Jules, Bill Adams, Fikret Berkes, Simone Ferreira de Athayde, Nigel Dudley, Eugene Hunn, Luisa Maffi, Kay Milton, David Rapport, Paul Robbins, Eleanor Sterling, Sue Stolton, Anna Tsing, Erin Vintinnerk y Sarah Pilgrim

2009 "The Intersections of Biological Diversity and Cultural Diversity : Towards Integration", Conservation and Society, 7 (2):100-112. DOI: 10.4103/09724923.58642 .

Real Academia Española (RAE)

2014 Diccionario de la Lengua Española, 23ạ edición, <http://dle.rae. es/?id $=$ Beoktf0 $>$ [Consultada el 2 de Noviembre 2017].

Ruz Lhuillier, Alberto

1995 Los antiguos mayas, 3a ed. México: Fondo de Cultura Económica, Secretaría de Agricultura, Ganadería, Desarrollo Rural, Pesca y Alimentación. 
Salgado Ramírez, Álvaro

2007 "La defensa y reconocimiento integral del conocimiento tradicional", Libres de Monopolios sobre el conocimiento y la vida. Hacia una convergencia de movimientos, pp. 89-92. Costa Rica: Fundación Vía Libre, GRAIN, Comunidades Ecologistas La Ceiba, Red de Coordinación en Biodiversidad, Fundación Heinrich Böll.

Santos, Boaventura De Sousa

2010 Descolonizar el saber, reiventando el poder. Montevideo: TRILCE, Extensión Universidad de la República.

Sotelo Santos, Laura Elena, María Elena Guerrero Gómez y Carlos Álvarez Asomoza

2012 "El cultivo tradicional de la abeja Melipona beecheii. Una constante del huerto familiar entre los mayas de Yucatán”, El huerto familiar del sureste de México, pp. 293-322, Ramón Mariaca Méndez (ed.). Villahermosa, San Cristóbal de las Casas: Secretaría de Recursos Naturales y Protección Ambiental de Tabasco, El Colegio de la Frontera Sur.

Stevenson, Marc G

1996 "Indigenous Knowledge in Environmental Assessment”, ARCTIC, 49 (3): 278291. DOI: 10.14430/arctic1203.

Swiderska, Krystina

2009 "Protecting Traditional Knowledge: A Holistic Approach Based on Customary Laws and Biocultural Heritage", Conserving and Valuing Ecosystem Services and Biodiversity, pp. 331-344, K. N. Ninan (ed.). London: Earthscan.

Silici, Laura

2014 "What is Agroecology?", Agroecology, What It Is And What It Has To Offer, pp. 6-11. London: International Institute for Enviroment and Development.

Spanish Oxford Living Dictionaries

2018 https://es.oxforddictionaries.com/definicion/conservacionista > [consultado el 18 de mayo del 2018].

Thompson, J. Eric S.

1975 Historia y Religión de los Mayas. México: Siglo XXI.

Toledo, Victor M.

2003 "Pueblos indios y biodiversidad: una visión planetaria", Ecología, espiritualidad y conocimiento, de la sociedad del riesgo a la sociedad sustentable, pp. 67-80. México: Programa de las Naciones Unidas para el Medio Ambiente, Universidad Iberoamericana.

2005 "La memoria tradicional: la importancia agroecológica de los saberes locales”, LEISA Revista de Agroecoklogía, 20 (4): 16-19.

2013 "El patrimonio biocultural en la mesa de discusión", Suplemento Cultural El Tlacuache, 3: 1-2. 
Toledo, Victor M. y Pablo Alarcón-Cháires

2012 "La etnoecología hoy: panorama, avances, desafíos", Etnoecológica, 9 (1): $1-16$.

Tudela, Fernando

1992 La modernización forzada del trópico: El caso de Tabasco. Proyecto Integrado del Golfo. México: Instituto Politécnico Nacional, Centro de Investigación y de Estudios Avanzados, Federación Internacional de Institutos de Estudios Avanzados, Instituto de Investigaciones de las Naciones Unidas para el Desarrollo Social, El Colegio de México.

Valdez Leal, Juan de Dios

2008 "Propuesta de monitoreo de fauna silvestre en el estado de Tabasco, Biodiversidad Mexicana, <http:/www.biodiversidad.gob.mx/corredor/cbmm/ DOC/41_306.pdf > [consultada el 20 de Sept 2017].

Valles, Miguel S.

2014 Entrevistas cualitativas. Segunda edición. Madrid: Centro de Investigaciones Sociológicas (Cuadernos Metodológicos, 32).

Vásquez-Dávila, Marco Antonio y María Beatriz Solís Trejo

1991 "Conocimiento, uso y manejo de la abeja nativa por los chontales de Tabasco”, Tierra y Agua, 2: 29-38.

Vautravers Tosca, Guadalupe y Aurora Marianela Ochoa Rivera

2008 "Las recientes transformaciones de la migración en Tabasco", Migraciones Internacionales, 5 (1): 65-91.

Xiu-Chacón, Gaspar

1998 "El arte curativo de los mayas y los primeros médicos de la península de Yucatán, México”, Revista Biomédica, 9: 38-43. 


\section{Anexo I}

\begin{tabular}{|l|c|}
\hline \multicolumn{2}{|c|}{$\begin{array}{c}\text { Especies de árboles utilizadas } \\
\text { para colmenas de tronco }\end{array}$} \\
\hline \multicolumn{1}{|c|}{$\begin{array}{c}\text { Número de } \\
\text { colmenas }\end{array}$} \\
\hline Aguacate & 9 \\
\hline Castaña (Artocarpus altilis) & 3 \\
\hline $\begin{array}{l}\text { Tatuán (Colubrina ferruginosa } \\
\text { Brong.) }\end{array}$ & 2 \\
\hline Guácimo (Guazuma ulmifolia) & 2 \\
\hline Hule (Castilla elastica) & 2 \\
\hline Jobo (Spondias mombin) & 2 \\
\hline Ficus sp. & 1 \\
\hline Anona (Annona reticulata L.) & 1 \\
\hline $\begin{array}{l}\text { Machiche (Lonchocarpus } \\
\text { cruentus Lundell) }\end{array}$ & 1 \\
\hline $\begin{array}{l}\text { Nance (Byrsonima crassifolia } \\
\text { (L.) Kunth) }\end{array}$ & 1 \\
\hline Pucté (Bucida Buceras L.) & 1 \\
\hline $\begin{array}{l}\text { Zapotillo (Pouteria } \\
\text { campechiana (Kunth) Baehmi) }\end{array}$ & 1 \\
\hline Bojón (Cordia alliodora) & 1 \\
\hline $\begin{array}{l}\text { Bolchiche (Coccoloba } \\
\text { barbadensis Jacq.) }\end{array}$ & 1 \\
\hline Cedro (Cedrela odorata) & 1 \\
\hline $\begin{array}{l}\text { Chelele blanco (Inga Laurina } \\
\text { (Sw.) Willd.) }\end{array}$ & $\begin{array}{l}\text { Ariajahua (Heliocarpus donnell- } \\
\text { smithii Rose) }\end{array}$ \\
\hline $\begin{array}{l}\text { Chipilin (Diphysa robinioides } \\
\text { Benth.) }\end{array}$ & 1 \\
\hline Coco & 1 \\
\hline Guayaba (Psidium guajava) \\
\hline (Ruiz\&Pav.) Oken)
\end{tabular}




\begin{tabular}{|l|c|}
\hline Moté (Erythrina americana) & 1 \\
\hline $\begin{array}{l}\text { Palo de agua (Pachira } \\
\text { aquatica) }\end{array}$ & 1 \\
\hline $\begin{array}{l}\text { Pochote (Cochlospermum } \\
\text { vitifolium) }\end{array}$ & 1 \\
\hline $\begin{array}{l}\text { Popiste (Blepharidium } \\
\text { mexicanum) }\end{array}$ & 1 \\
\hline $\begin{array}{l}\text { Quebracha (Aphananthe } \\
\text { monoica (Hemsl.) J.F. Leroy) }\end{array}$ & 1 \\
\hline $\begin{array}{l}\text { Tinto (Haematoxylum } \\
\text { campechianum) }\end{array}$ & 1 \\
\hline $\begin{array}{l}\text { Tukuy (Pithecellobium } \\
\text { lanceolatum) }\end{array}$ & 1 \\
\hline
\end{tabular}




\section{Anexo II}

\begin{tabular}{|c|c|}
\hline \multicolumn{2}{|c|}{$\begin{array}{l}\text { Relación de flora melífera identificada } \\
\text { por los meliponicultores }\end{array}$} \\
\hline Flores & $\begin{array}{l}\text { Número de } \\
\text { menciones }\end{array}$ \\
\hline Mango (Mangifera indica L.) & 13 \\
\hline Naranja (Citrus sinensis (L.) Osbeck) & 13 \\
\hline $\begin{array}{l}\text { Tinto (Haematoxylum campechianum } \\
\text { L.) }\end{array}$ & 7 \\
\hline Maculis (Tabebuia rosea (Bertol.) DC) & 6 \\
\hline Guaya (Melicoccus oliviformis Kunth) & 5 \\
\hline Guayaba (Psidium guajava L.) & 5 \\
\hline Limón (Citrus limon L.) & 5 \\
\hline $\begin{array}{l}\text { Nance (Byrsonima crassifolia }(L .) \\
\text { Kunth) }\end{array}$ & 5 \\
\hline Árboles de montaña & 4 \\
\hline Cítricos & 4 \\
\hline Achiote (Bixa Orellana L.) & 3 \\
\hline $\begin{array}{l}\text { Cocoite (Gliricidia Sepium (Jacq.) } \\
\text { Kunth ex Walp.) }\end{array}$ & 3 \\
\hline Guacimo (Guazuma ulmifolia Lam) & 3 \\
\hline $\begin{array}{l}\text { Gusano (Lonchocarpus hondurensis } \\
\text { Benth). }\end{array}$ & 3 \\
\hline Palo sangre (Pterocarpus hayesii Hemls) & 3 \\
\hline Cacao (Theobroma cacao L.) & 2 \\
\hline Capulín (Muntingia calabura L.) & 2 \\
\hline Ceiba (Ceiba pentandra) & 2 \\
\hline Espiga del maíz (Zea mays) & 2 \\
\hline Flores de ornato??? & 2 \\
\hline Tulipán (Tulipan sp.) & 2 \\
\hline Albahaca (Ocimum basilicum L.) & 1 \\
\hline Azucenas (Lilium candidum L.) & 1 \\
\hline
\end{tabular}




\begin{tabular}{|c|c|}
\hline $\begin{array}{l}\text { Bari (Calophyllum brasiliense } \\
\text { Cambess.) }\end{array}$ & 1 \\
\hline $\begin{array}{l}\text { Bojón (Cordia alliodora (Ruiz \& Pav.) } \\
\text { Oken) }\end{array}$ & 1 \\
\hline $\begin{array}{l}\text { Boloconté (Eugenia } \\
\text { dominguensis Berg.) }\end{array}$ & 1 \\
\hline $\begin{array}{l}\text { Candelero (Cordia stellifera I.M. } \\
\text { Johnst.) }\end{array}$ & 1 \\
\hline Caoba (Swetenia macrophylla Kin) & 1 \\
\hline $\begin{array}{l}\text { Caracolillo (Cojoba arbórea Britton \& } \\
\text { Rose) }\end{array}$ & 1 \\
\hline Carambola (Averrhoa carambola L.) & 1 \\
\hline $\begin{array}{l}\text { Chaschin (Sideroxylon persimile } \\
\text { (Hemsl.) T.D Penn) }\end{array}$ & 1 \\
\hline Chaculí & 1 \\
\hline $\begin{array}{l}\text { Chakaj rojo (Bursera simaruba (L.) } \\
\text { Sarg) }\end{array}$ & 1 \\
\hline $\begin{array}{l}\text { Chicozapote (Manilkara zapota (L.) } \\
\text { Royen) }\end{array}$ & 1 \\
\hline Chigua & 1 \\
\hline Ciruela (Spondias purpurea L.) & 1 \\
\hline Coco (Cocos nucifera L.) & 1 \\
\hline $\begin{array}{l}\text { Corozo (Attalea butyracea (Mutis ex } \\
\text { L.f.) Wesss. Boer.) }\end{array}$ & 1 \\
\hline Corona de cristo (Euphorbia milii) & 1 \\
\hline Crucillo (Randia echinocarpa) & 1 \\
\hline Dormilona (Mimosa pudica) & 1 \\
\hline Es de acuerdo a cada especie de abeja & 1 \\
\hline Flamboyan (Delonix regia (Bojer) Raf.) & 1 \\
\hline Flor de mayo (Plumeria rubra L.) & 1 \\
\hline Flor de violeta (Viola odorata) & 1 \\
\hline Flores rojas & 1 \\
\hline Frijol (Phaseolus vulgaris L.) & 1 \\
\hline Guanabana (Annona muricata L.) & 1 \\
\hline $\begin{array}{l}\text { Guanacaste (Enterolobium cyclocarpum } \\
\text { (Jacq.) Griseb) }\end{array}$ & 1 \\
\hline
\end{tabular}




\begin{tabular}{|l|c|}
\hline $\begin{array}{l}\text { Guapaque (Dialium guianense (Aubl.) } \\
\text { Sandw.) }\end{array}$ & 1 \\
\hline $\begin{array}{l}\text { Guarumo (Cecropia obtusifolia } \\
\text { Bertol.) }\end{array}$ & 1 \\
\hline $\begin{array}{l}\text { Guayacan (Guaiacum sanctum L., } \\
\text { Zygophy - llaceae) }\end{array}$ & 1 \\
\hline Gusano de montaña & 1 \\
\hline Hierba Jade & 1 \\
\hline Jobo (Spondias mombin L.) & 1 \\
\hline $\begin{array}{l}\text { Jolotzin (Heliocarpus appendiculatus } \\
\text { Turcz) }\end{array}$ & 1 \\
\hline Limoncillo (Trichilia havanensis jacq.) & 1 \\
\hline Lluvia de oro (Laburnum anagyroides) & 1 \\
\hline Maculí de montaña & 1 \\
\hline $\begin{array}{l}\text { Majahua (Heliocarpus donnell-smithii } \\
\text { Rose) }\end{array}$ & 1 \\
\hline Naranja (Citrus sinensis) & 1 \\
\hline Piedra Caliza & 1 \\
\hline Pimienta gorda (Pimenta dioica) & 1 \\
\hline Popiste (Blepharidium arboreum) & 1 \\
\hline Pozol agrio (Dendropanax arboreus L.) & 1 \\
\hline Ramón (Brosimum alicastrum Swarts) & 1 \\
\hline $\begin{array}{l}\text { Tinto (Haematoxylum campechianum } \\
\text { L.) }\end{array}$ & 1 \\
\hline $\begin{array}{l}\text { Palencano (Trichospermum mexicanum } \\
\text { DC.) Baill) }\end{array}$ & 1 \\
\hline Palo de san Diego & 1 \\
\hline Papaya (Carica papaya L.) & 1 \\
\hline Papaya de montaña & 1 \\
\hline Pucté (Bucida buceras L.) & 1 \\
\hline Rambutan (Nephelium lappaceum L.) & 1 \\
\hline Ramón (Brosimum Alicastrum Sw.) & 1 \\
\hline Rosas (Rosa sp.) & 1 \\
\hline
\end{tabular}




\begin{tabular}{|l|c|}
\hline Tamarindo (Tamarindus indica L.) & 1 \\
\hline Tantinche & 1 \\
\hline Trigo (Triticum sp.) & 1 \\
\hline $\begin{array}{l}\text { Tukuy (Pithecellobium lanceolatum } \\
\text { (Humb. \& Bonpl. ex Willd.) Benth) }\end{array}$ & 1 \\
\hline Zacates & 1 \\
\hline Zapote de agua (Pachira aquatica) & 1 \\
\hline
\end{tabular}




\section{Anexo III}

\begin{tabular}{|c|c|}
\hline $\begin{array}{c}\text { Especies de árboles } \\
\text { donde encuentran nidos }\end{array}$ & $\begin{array}{l}\text { Número de } \\
\text { menciones }\end{array}$ \\
\hline Aguacate (Persea americana) & 6 \\
\hline Melina (Gmelina arborea Roxb) & 4 \\
\hline Guapaque (Dialium guianense) & 3 \\
\hline $\begin{array}{l}\text { Canshán (Terminalia amazonia } \\
\text { (J.F.Gmel.) Exell.) }\end{array}$ & 3 \\
\hline Cocoite (Gliricidia Sepium (Jacq.) Steud.) & 2 \\
\hline Guayaba (Psidium guajava L.) & 2 \\
\hline $\begin{array}{l}\text { Palencano (Trichospermum mexicanum } \\
\text { (DC.)Baill.) }\end{array}$ & 2 \\
\hline Zapote (Manilkara zapota (L.) P. Royen) & 2 \\
\hline Awate & 1 \\
\hline Barí (Calophyllum brasiliense) & 1 \\
\hline $\begin{array}{l}\text { Bayo (Aspidosperma megalocarpon Mull. } \\
\text { Arg.) }\end{array}$ & 1 \\
\hline Castaña (Castanea sativa) & 1 \\
\hline Chakaj o Mulato (Bursera simaruba) & 1 \\
\hline Chichica & 1 \\
\hline $\begin{array}{l}\text { Chicozapote (Manilkara zapota (L.) P. } \\
\text { Royen) }\end{array}$ & 1 \\
\hline Chicozapote de montaña & 1 \\
\hline Chimon o Amate (Ficus insípida Willd.) & 1 \\
\hline Ciruela (Spondias purpurea L.) & 1 \\
\hline $\begin{array}{l}\text { Cola de lagarto (Zanthoxylum } \\
\text { riedelianum) }\end{array}$ & 1 \\
\hline Cualquier árbol & 1 \\
\hline $\begin{array}{l}\text { Cucharo (Andira inermis (W. Wright) } \\
\text { Kunth ex DC) }\end{array}$ & 1 \\
\hline $\begin{array}{l}\text { Dzalam (Lysiloma latisiliquum (L.) } \\
\text { Benth.) }\end{array}$ & 1 \\
\hline Guacamaya (Xylopia frutescens) & 1 \\
\hline $\begin{array}{l}\text { Gusano (Lonchocarpus hondurensis } \\
\text { Benth). }\end{array}$ & 1 \\
\hline
\end{tabular}




\begin{tabular}{|l|c|}
\hline Jobillo (Hura Crepitans L.) & 1 \\
\hline $\begin{array}{l}\text { Jolotzin (Heliocarpus appendiculatus } \\
\text { Turcz) }\end{array}$ & 1 \\
\hline Kakate & 1 \\
\hline Luin (Ampelocera hottlei (Standl.) Standl.) & 1 \\
\hline $\begin{array}{l}\text { Majahua (Heliocarpus donnell-smithii } \\
\text { Rose) }\end{array}$ & 1 \\
\hline Majagua blanca & 1 \\
\hline Mulato & 1 \\
\hline
\end{tabular}

